TAO, Vol. 16, No. 4, 745-762, October 2005

\title{
Hydrochemical Changes in Spring Waters in Taiwan: Implications for Evaluating Sites for Earthquake Precursory Monitoring
}

\author{
Sheng-Rong Song ${ }^{1, *}$, Yaw-Lin Chen ${ }^{1}$, Chia-Mei Liu ${ }^{1}$, Wei-Yi Kü ${ }^{1}$, Huei-Fen Chen ${ }^{1}$, Ya-Jiun Liu ${ }^{1}$, \\ Li-Wei Kuo ${ }^{1}$, Tsanyao Frank Yang ${ }^{1}$, Cheng-Hong Chen ${ }^{1}$, Tsung-Kwei Liu ${ }^{1}$ and Ming Lee ${ }^{2}$
}

(Manuscript received 16 January 2005, in final form 21 July 2005)

\begin{abstract}
To evaluate potential monitoring sites as well as useful ions which are capable of serving as earthquake precursors, ten subsurface water bodies in different tectonic domains in southwestern, northern and northeastern Taiwan were selected. They included the deep circulation of hot springs, shallower artesian springs and groundwater. Most of the hot springs clearly show chemical anomalies which correlate with earthquake events during the monitoring periods. Against this, the groundwater does not correspond to any events. Hot springs from deeper reservoirs are superior to artesian springs and groundwater from shallower reservoirs. The artesian spring from the smaller subsurface water body is superior to the groundwater from larger reservoirs. Aside from this, anions, especially chloride, outperform cations as geochemical precursors for earthquake monitoring. It is unambiguous that the major factors that determine the usefulness of chemical anomalies in the waters for earthquake precursory monitoring are the kinds, the depths and the size of reservoirs and the ion species of the subsurface water bodies.
\end{abstract}

(Key words: Earthquake precursory, Taiwan, Hydrochemistry, Hot spring, Artesian spring)

\section{INTRODUCTION}

Besides being the most unpredictable events known to mankind, earthquakes are undeniably the most destructive hazards in nature. Identifying useful short-term precursors of

\footnotetext{
${ }^{1}$ Department of Geosciences, National Taiwan University, Taipei, Taiwan, ROC

2 Central Geological Survey, MOEA

* Corresponding author address: Dr. Sheng-Rong Song, Department of Geosciences, National Taiwan University, Taipei, Taiwan, ROC; E-mail: srsong@ntu.edu.tw
} 
earthquakes, therefore, has long been a major goal of geoscientists. In the past, substantive evidence in support of many diverse kinds of precursors, including hydrological and chemical changes in subsurface fluids prior to or at the same time as a large earthquake, has been found. Among these are valuable, insightful precursory changes in gases involved in both hydrothermal processes, like $\mathrm{Rn}, \mathrm{He}, \mathrm{CO}_{2}, \mathrm{CH}_{4}, \mathrm{H}_{2}, \mathrm{Ar}$ and $\mathrm{N}_{2}$, and in water chemistry, like $\mathrm{Cl}^{-}, \mathrm{F}^{-}$, $\mathrm{NO}_{3}{ }^{-}$and $\mathrm{SO}_{4}{ }^{2-}$ (Hauksson 1981; King 1986; Tsunogai and Wakita 1995, 1996; Sugisaki et al. 1996; Toutain et al. 1997; Chyi et al. 2005; Italiano et al. 2005; Ramirez-Guzman et al. 2005; Walia et al. 2005; Yang et al. 2005). Such geochemical anomalies are generally associated with changes in a subsurface water circulating system in the process of earthquake generation (Thomas 1988; Rojstaczer and Wolf 1992; Muir-Wood and King 1993; Rojstaczer et al. 1995; Sugisaki et al. 1996). In a broad sense, in countries with high seismicity, to monitor data on cations, anions and transitional metals in groundwater is to frequently obtain highly constructive information for earthquake prediction (Barsukov et al. 1984/1985; Guiru et al. 1984/1985; Koizumi et al. 1985; Tsunogai and Wakita 1995, 1996; Toutain et al. 1997; Satake et al. 2002; Song et al. 2003, 2005; Claesson et al. 2004). Such solid evidence notwithstanding, it is not always the rule that chemical anomalies are sensitive enough to serve as earthquake precursors at monitoring sites. What is necessary to bear in mind, therefore, is that the choice of the best working sites and the most useful ions underpins the effectiveness of earthquake precursory monitoring.

The highly destructive 1999 Chi-Chi earthquake (magnitude $\mathrm{M}_{\mathrm{L}}=7.3$ ) with surface ruptures totaling about $80-90 \mathrm{~km}$ in length along the Chelungpu fault and with the largest measured vertical offsets extending as long as $5-8 \mathrm{~m}$ occurred near the town of Chi-Chi in Nantou County in west-central Taiwan. The epicenter was located about $15 \mathrm{~km}$ east of the surface trace of the thrust fault at $120.82^{\circ} \mathrm{E}$ and $23.85^{\circ} \mathrm{N}$, while the hypocenter depth was roughly $12 \mathrm{~km}$ (Chung and Shin 1999; Kao and Chen 2000). One of the largest inland events in the past century in Taiwan, the Chi-Chi earthquake caused the death of some 2400, injured another 10000 and destroyed more than 100000 buildings.

After the Chi-Chi earthquake, a large-scale research program to monitor active faults and identify earthquake precursors was jointly initiated in 2000 by the Central Geological Survey, the MOEA-ROC and the Institute of Geosciences, National Taiwan University. In one subprogram, over the past five years, weekly measurements of cation and anion concentrations were made in both hot and artesian springs and groundwater in Taiwan in an effort to both establish background concentrations and identify earthquake-related anomalies. The purpose was to evaluate potential sites that would be the most valuable for setting up regular monitoring systems in the future. This paper presents the results from the 5-year evaluation of potential sites with hot and artesian springs and groundwater wells in southwestern, northern and northeastern Taiwan. It also suggests guidelines as to the best way to choose such monitoring sites.

\section{SAMPLING AND ANALYSES}

To evaluate the potential of chemical ions and subsurface water bodies to serve as earth- 
quake precursors, nine sites with ten hot and artesian springs and groundwater with different depths in southwestern, northern and northeastern Taiwan (Fig. 1) had been selected for regular sampling on the basis of their geological conditions, the water species and their accessibility for long-term sampling. These sites are in locations with different geological and structural conditions, namely, the Pre-Miocene metamorphic terrain, i.e., the Yuanshan hot spring; the Miocene sedimentary formations in the Western Foothills, i.e., the Kuantzeling hot and artesian springs, the two deep wells at Chingshan and the Tapu hot springs; and the recent fluvial deposits, i.e., the Meinong, Tashu, Chaochou and Yuanshan groundwater. Sampling was done once every three days for the duration of at least one year, thereby covering different seasons, including the dry and rainy ones (Table 1).

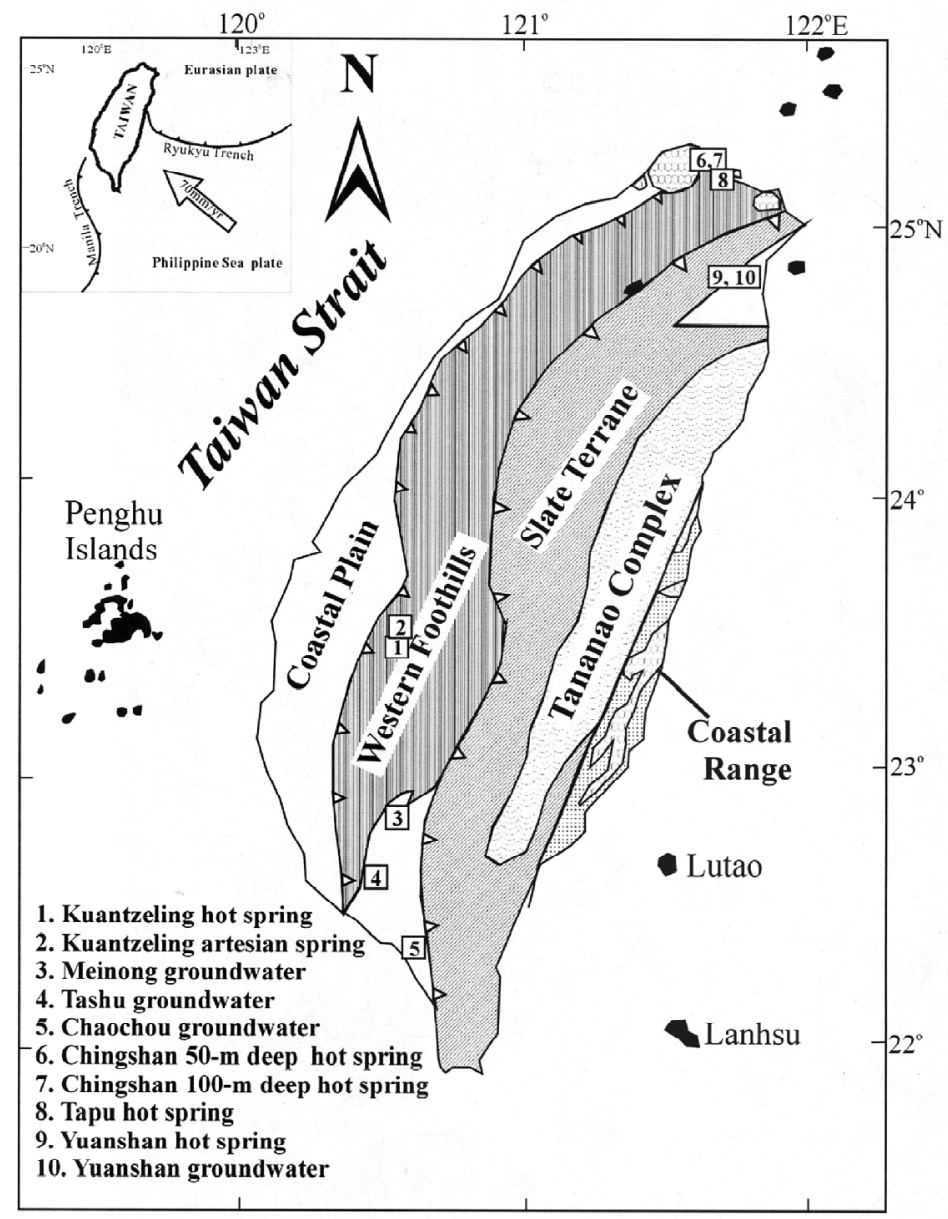

Fig. 1. Geological map of Taiwan with the locations of the monitoring sites marked $1-10$. Inset map shows the tectonics in the vicinity of Taiwan (modified from Ho 1986). 
Table 1. Monitoring period, sampling interval, numbers of sample and correlated to earthquake events of ten monitoring sites.

\begin{tabular}{|c|c|c|c|c|c|c|c|c|}
\hline \multirow{2}{*}{ Site } & \multirow{2}{*}{$\begin{array}{c}\text { Monitoring } \\
\text { period }\end{array}$} & \multirow{2}{*}{$\begin{array}{l}\text { Sampling } \\
\text { interval }\end{array}$} & \multirow{2}{*}{$\begin{array}{l}\text { Number } \\
\text { of samples }\end{array}$} & \multicolumn{5}{|c|}{ Earthquake events of $\mathrm{M}_{\mathrm{L}}^{+}$} \\
\hline & & & & Date & Longitude (E) & Latitude $(\mathrm{N})$ & Magnitude & Intensity \\
\hline \multirow{8}{*}{ Kuantzeling hot spring } & \multirow{8}{*}{$\begin{array}{l}1999 / 07 / 15 \sim \\
2001 / 08 / 01\end{array}$} & \multirow{8}{*}{3 days } & \multirow{8}{*}{210} & $1999 / 09 / 21$ & 120.85 & $23.61^{\circ}$ & 7.3 & 5 \\
\hline & & & & $1999 / 10 / 22$ & $120.40^{\circ}$ & $23.51^{\circ}$ & 6.4 & 6 \\
\hline & & & & $1999 / 11 / 15$ & $120.51^{\circ}$ & $23.49^{\circ}$ & 5.2 & 5 \\
\hline & & & & $2000 / 04 / 12$ & 120.54 & $23.50^{\circ}$ & 4.1 & 4 \\
\hline & & & & $2000 / 06 / 11$ & $121.11^{\circ}$ & $23.89^{\circ}$ & 6.7 & 5 \\
\hline & & & & $2000 / 11 / 01$ & $120.49^{\circ}$ & $23.43^{\circ}$ & 4.1 & 4 \\
\hline & & & & $2001 / 02 / 09$ & $120.63^{\circ}$ & $23.42^{\circ}$ & 4.9 & 4 \\
\hline & & & & $2001 / 04 / 24$ & $120.46^{\circ}$ & $23.46^{\circ}$ & 4.0 & 4 \\
\hline \multirow{2}{*}{ Chingshan-50 $\mathrm{m}$ hot spring } & \multirow{2}{*}{$\begin{array}{l}2002 / 01 / 11 \sim \\
2003 / 10 / 23\end{array}$} & \multirow{2}{*}{3 days } & \multirow{2}{*}{174} & $2003 / 09 / 07$ & $122.82^{\circ}$ & $24.56^{\circ}$ & 4.3 & 2 \\
\hline & & & & $2003 / 10 / 09$ & $121.96^{\circ}$ & $24.04^{\circ}$ & 4.6 & 3 \\
\hline \multirow{5}{*}{ Chingshan- $100 \mathrm{~m}$ hot spring } & \multirow{5}{*}{$\begin{array}{c}2002 / 01 / 11 \\
2003 / 10 / 23\end{array}$} & \multirow{5}{*}{3 days } & \multirow{5}{*}{174} & $2002 / 09 / 08$ & $121.68^{\circ}$ & $24.45^{\circ}$ & 5.7 & 3 \\
\hline & & & & $2002 / 10 / 18$ & $121.76^{\circ}$ & $24.24^{\circ}$ & 4.9 & 4 \\
\hline & & & & $2002 / 11 / 02$ & $121.92^{\circ}$ & $24.42^{\circ}$ & 4.7 & 3 \\
\hline & & & & $2002 / 12 / 17$ & $121.89^{\circ}$ & $24.45^{\circ}$ & 3.9 & 4 \\
\hline & & & & $2003 / 04 / 02$ & $121.79^{\circ}$ & $24.30^{\circ}$ & 4.1 & 3 \\
\hline Tapu hot spring & $\begin{array}{l}2002 / 01 / 11 \sim \\
2003 / 10 / 23\end{array}$ & 3 days & 207 & $2002 / 12 / 17$ & $121.89^{\circ}$ & $24.45^{\circ}$ & 3.9 & 4 \\
\hline \multirow{2}{*}{ Yuanshan hot spring } & $2003 / 03 / 01 \sim$ & \multirow{2}{*}{3 days } & \multirow{2}{*}{77} & $2003 / 05 / 26$ & $121.69^{\circ}$ & $24.70^{\circ}$ & 4.9 & 2 \\
\hline & $2003 / 10 / 20$ & & & $2003 / 10 / 01$ & $121.77^{\circ}$ & $24.47^{\circ}$ & 3.4 & 3 \\
\hline \multirow{3}{*}{ Kuantzeling artesian spring } & \multirow{3}{*}{$\begin{array}{c}2000 / 01 / 07 \\
2001 / 08 / 29\end{array}$} & \multirow{3}{*}{3 days } & \multirow{3}{*}{174} & $2000 / 04 / 12$ & $120.54^{\circ}$ & $23.50^{\circ}$ & 4.1 & 4 \\
\hline & & & & $2000 / 06 / 11$ & $121.11^{\circ}$ & $23.89^{\circ}$ & 6.7 & 5 \\
\hline & & & & $2000 / 07 / 16$ & $122.29^{\circ}$ & $20.16^{\circ}$ & 7.0 & 2 \\
\hline Mcinong groundwater & $\begin{array}{l}2000 / 01 / 05 \sim \\
2001 / 01 / 18 \\
\end{array}$ & 3 days & 69 & - & - & - & $\cdots$ & -- \\
\hline Tashu groundwater & $\begin{array}{c}1990 / 11 / 26 \sim \\
2001 / 01 / 04\end{array}$ & 3 days & 63 & -- & - & -- & -- & - \\
\hline Chaochou groundwater & $\begin{array}{l}2000 / 01 / 08 \sim \\
2001 / 01 / 17\end{array}$ & 3 days & 104 & -- & -- & -- & -- & -- \\
\hline Yuanshan groundwater & $\begin{array}{c}2003 / 02 / 27 \sim \\
2003 / 10 / 20\end{array}$ & 3 days & 85 & -- & -- & -- & -- & -- \\
\hline
\end{tabular}

*: Data from the Central Weather Bureau of Taiwan (CWBT) (2004).

--: non-correlated earthquake events.

Dissolved anions $\left(\mathrm{F}^{-}, \mathrm{Cl}^{-}, \mathrm{Br}^{-}, \mathrm{NO}_{3}{ }^{-}, \mathrm{PO}_{4}{ }^{3-}, \mathrm{SO}_{4}{ }^{2-}\right)$ and cations $\left(\mathrm{Na}^{+}, \mathrm{K}^{+}, \mathrm{Ca}^{2+}\right.$, $\mathrm{Mg}^{2+}, \mathrm{Si}^{4+}$ ) were measured with an ion chromatographer (IC, Type Dionex DX-100) and an inductively coupled plasma-atomic emission spectrometer (ICP-AES, Type Jobin-Yvon JY38plus), respectively. Samples from the same spring were measured in duplicate to confirm the precision of the measurements. Analytical uncertainties in the absolute concentrations were less than $3 \%$ for all of the anions and less than $5 \%$ for all of the cations. 


\section{TEMPORAL VARIATIONS IN THE CHEMICAL COMPOSITION}

\subsection{Hot springs}

Four sites which comprised five hot springs were chosen for regular sampling for earthquake precursory monitoring. They are the Kuantzeling hot spring in the SW Taiwan, the two deep wells at the Chingshan hot spring with the depth of 50 and $100 \mathrm{~m}$ and the $40-\mathrm{m}$ deep well at the Tapu hot spring in the N Taiwan, and the Yuanshan hot spring in the NE Taiwan. The sampling periods roughly spanned from one to two years.

The temporal variations for the $\mathrm{Cl}^{-}$and $\mathrm{SO}_{4}{ }^{2-}$ concentrations of the water samples in these five hot springs are shown in Figs. 2 - 6, respectively. The average concentration and the two-sigma relative standard deviations $(2 \sigma)$ were calculated for each of the samples from the hot springs and are also plotted in the same figures and listed in Table 2. The $2 \sigma$ domains can be considered representative of the background values of the hot spring waters, values which may have resulted from water-rock interactions in the deep circulation of the subsurface reservoirs, from sampling heterogeneity or from analytical uncertainties. Values higher than $2 \sigma$, thus identified as anomalies, occurred during the sampling periods. Except for the chloride and sulfate ions, all of the cations and anions in these five hot springs varied within the $2 \sigma$ domains during the entire sampling period.

The chloride ion is the major anion in the Kuantzeling hot spring, with its average concentration reaching $2201 \pm 264 \mathrm{ppm}$. The average concentration of the sulfate ion is $33.6 \pm 12.4 \mathrm{ppm}$. The two-sigma relative standard deviation $(2 \sigma)$ of the two ions is $30.9 \%\left(\mathrm{Cl}^{-}\right)$and $18.0 \%$ $\left(\mathrm{SO}_{4}{ }^{2-}\right)$. Except for a few periods, the concentration of chloride in the different samples is, by and large, almost always constant, unlike that for sulfates, which has greater fluctuations particularly in two periods, i.e., from March 2000 to June 2000 and from December 2000 to February 2001 (Figs. 2A, B). Chloride anomalies occur around September 20, October 1 and

Table 2. The average concentrations (ppm) of anions and cations of subsurface waters from ten monitoring sites.

\begin{tabular}{|c|c|c|c|c|c|c|c|c|}
\hline Site & $\mathrm{Cl}^{-}$ & $\mathrm{NO}_{3}^{-}$ & $\mathrm{SO}_{4}{ }^{2-}$ & $\mathrm{Na}^{+}$ & $\mathrm{K}^{+}$ & $\mathrm{Ca}^{2+}$ & $\mathrm{Mg}^{2+}$ & $\mathrm{Si}^{4+}$ \\
\hline Kuantzeling hot spring & $2201 \pm 264$ & $8.16 \pm 2.96$ & $33.6 \pm 12.4$ & $5302 \pm 766$ & $146.0 \pm 88.4$ & bdl & $7.16 \pm 4.36$ & $16.3 \pm 12.6$ \\
\hline Chingshan-50 $\mathrm{m}$ hot spring & $618.0 \pm 28.4$ & bdl & $1860 \pm 19.8$ & $101.0 \pm 17.2$ & $46.7 \pm 7.1$ & $192.0 \pm 21.0$ & bdl & $35.4 \pm 4.8$ \\
\hline Chingshan- $100 \mathrm{~m}$ hot spring & $304.0 \pm 99.8$ & bdl & $71.1 \pm 19.1$ & $146.0 \pm 34.0$ & $46.4 \pm 6.7$ & $80.0 \pm 28.6$ & bdl & $34.5 \pm 11.0$ \\
\hline Tapu hot spring & $6048 \pm 1656$ & bdl & $2471 \pm 512$ & $2249 \pm 332$ & $285.0 \pm 16.4$ & $305.0 \pm 14.4$ & $255.0 \pm 31.6$ & $101.0 \pm 10.4$ \\
\hline Yuanshan hot spring & $56.0 \pm 17.3$ & bdl & $6.95 \pm 1.25$ & $165.0 \pm 10.0$ & bdl & $25.4 \pm 5.2$ & bdl & $14.8 \pm 1.4$ \\
\hline Kuantzeling artesian spring & $2.70 \pm 0.82$ & bdl & $25.4 \pm 4.5$ & $11.6 \pm 8.7$ & $b \mathrm{dl}$ & $107.0 \pm 58.8$ & $50.6 \pm 15.9$ & $7.26 \pm 4.60$ \\
\hline Meinong groundwater & $11.4 \pm 1.8$ & $14.80 \pm 4.66$ & $80.8 \pm 17.3$ & 43. $0+9.1$ & bdl & $81.6 \pm 11.5$ & $25.4 \pm 2.8$ & $3.53 \pm 0.47$ \\
\hline Tashu groundwater & $13.6 \pm 2.5$ & bdl & $58.5 \pm 10.1$ & $28.7 \pm 3.1$ & bdl & $37.4 \pm 4.0$ & $36.2 \pm 3.2$ & $4.43 \pm 0.79$ \\
\hline Chaochou groundwater & $2.80 \pm 0.60$ & $15.70 \pm 3.76$ & $48.9 \pm 4.1$ & $12.3 \pm 2.7$ & bdl & $63.6+2.5$ & $14.2 \pm 0.7$ & $3.10 \pm 0.19$ \\
\hline Yuanshan groundwater & $3.73 \pm 2.66$ & bdl & $16.0 \pm 2.7$ & $5.06 \pm 1.09$ & bdl & bdl & bdl & $7.53 \pm 0.90$ \\
\hline
\end{tabular}

bdl: Below the detection limits. 


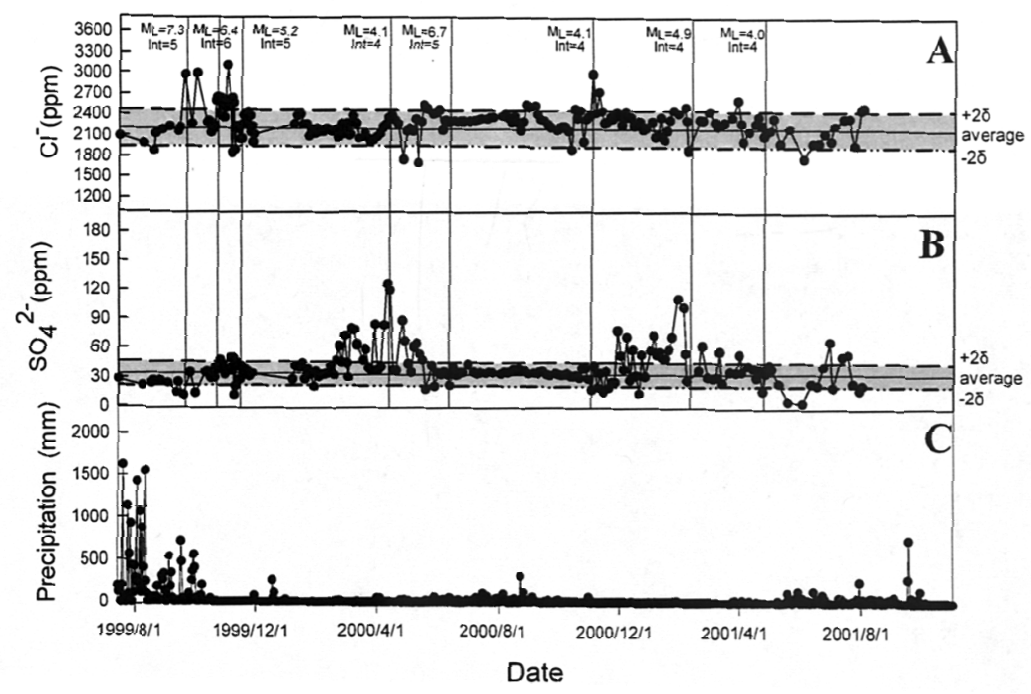

Fig. 2. Temporal variations of (A) $\mathrm{Cl}^{-}$and (B) $\mathrm{SO}_{4}{ }^{2-}$ concentrations in the Kuantzeling hot spring. The vertical lines represent chemical anomalies which correlate with earthquake events that occurred in this area. (C) Daily precipitation obtained in the Kuantzeling rain gauge station (data from the CWBT).

October 21 of 1999; April 25 and November 1 of 2000; and February 23 of 2001, and the duration of the anomalies range from a few to over twenty days. As for the sulfate concentration, two major anomalous events are detected around April 1, 2000 and January 27, 2001, and the duration is from just a few days to up to one month. Based on the date of earthquake occurred and intensity recorded in the seismic station near the monitoring site, those chemical anomalous events can be well correlated to the earthquakes (Figs. 2A, B). The epicenters of the earthquakes having probably induced the chemical anomalies were predominantly located in central Taiwan which is very near the monitoring site (Fig. 7). Furthermore, the Kuantzeling hot spring has recorded the chemical anomaly to respond the event of Chi-Chi earthquake and we have reported it in another paper (Song et al. 2005).

The chloride ion is also the major anion in both the 50-m and the 100-m deep Chingshan hot springs, and the respective average concentration at these sites reaches $618.0 \pm 28.4 \mathrm{ppm}$ and $304.0 \pm 99.8 \mathrm{ppm}$; contrast this with the respective average concentration of the sulfate ion which is $186.0 \pm 19.8 \mathrm{ppm}$ and $71.1 \pm 19.1 \mathrm{ppm}$. The two-sigma relative standard deviation $(2 \sigma)$ in these two hot springs is respectively $4.6 \%$ and $32.8 \%$ for $\mathrm{Cl}^{-}$, and $26.9 \%$ and $10.6 \%$ for $\mathrm{SO}_{4}{ }^{2-}$. For the most part, the concentration of chloride and sulfate in each of these samples was almost constant, except during a few periods (Figs. 3A, B and 4A, B). The chloride anomalies occur around September 9, October 15, November 1 and December 9 of 2002, and March 28 and October 4 of 2003, while the sulfate anomalies occur around December 9 of 2002, and April 14, September 5 and October 4 of 2003, and these anomalies just last a few 


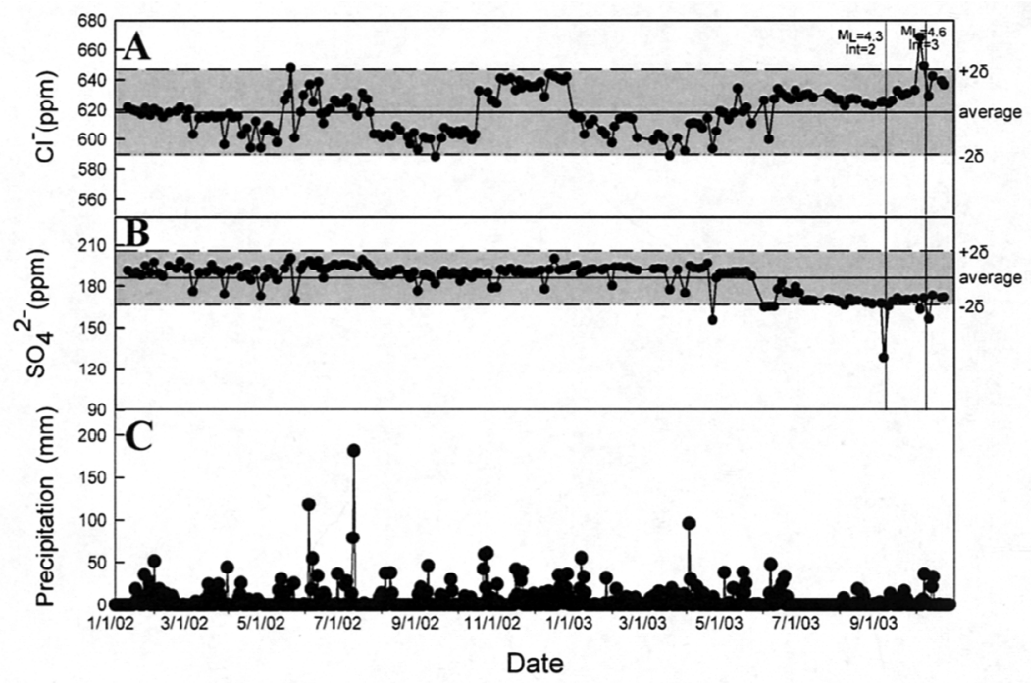

Fig. 3. Temporal variations of (A) $\mathrm{Cl}^{-}$and (B) $\mathrm{SO}_{4}{ }^{2-}$ concentrations in the 50-m deep Chingshan hot spring. The vertical lines represent the same as Fig. 2. (C) Daily precipitation recorded in the Chingshan rain gauge station (data from the CWBT).

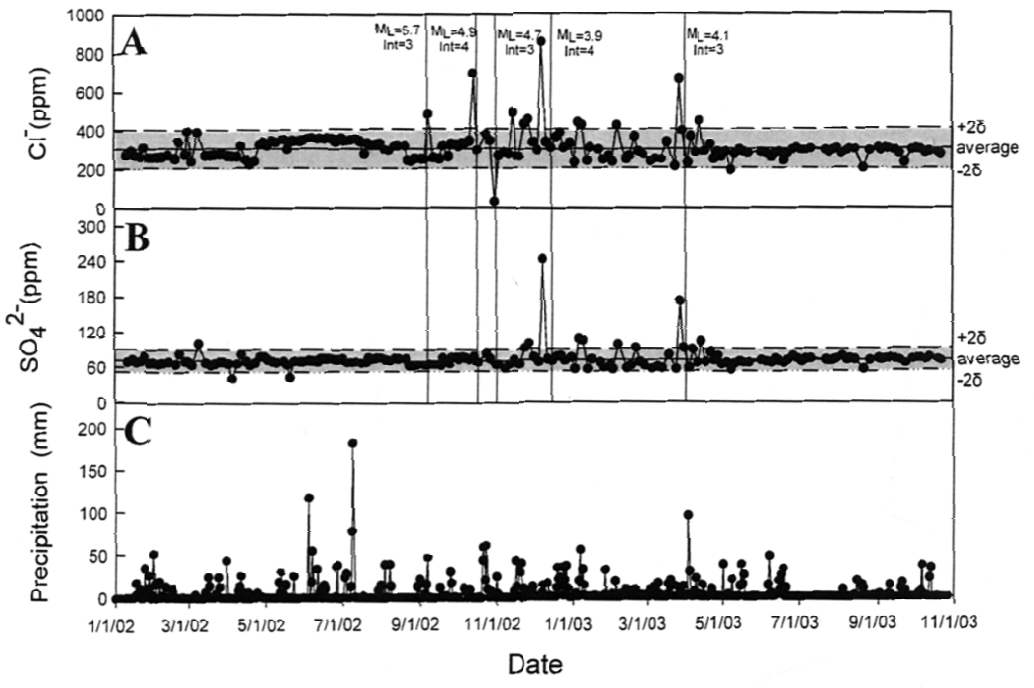

Fig. 4. Temporal variations of (A) $\mathrm{Cl}^{-}$and (B) $\mathrm{SO}_{4}{ }^{2-}$ concentrations in the 100-m deep Chingshan hot spring. The vertical lines represent the same as Fig. 2. (C) Daily precipitation record is the same as Fig. 3. 
days. Most of the epicenters of the earthquakes that could have induced the chemical anomalies were predominantly in the inland of northeast Taiwan, while few in the offshore (Fig. 7).

The chloride and sulfate ions are again the major anions in the Tapu hot spring, and their average concentration reaches $6048 \pm 1656 \mathrm{ppm}$ and $2471 \pm 512 \mathrm{ppm}$, respectively. The twosigma relative standard deviation $(2 \sigma)$ is $27.4 \%$ for $\mathrm{Cl}^{-}$and $20.7 \%$ for $\mathrm{SO}_{4}{ }^{2-}$. As a rule, the respective concentration in the samples from this site is almost constant, except during one period (Figs. 5A, B). Only one chloride and one sulfate anomaly is identified, and both occur almost simultaneously around December 11, 2002, with a duration of just a few days. The

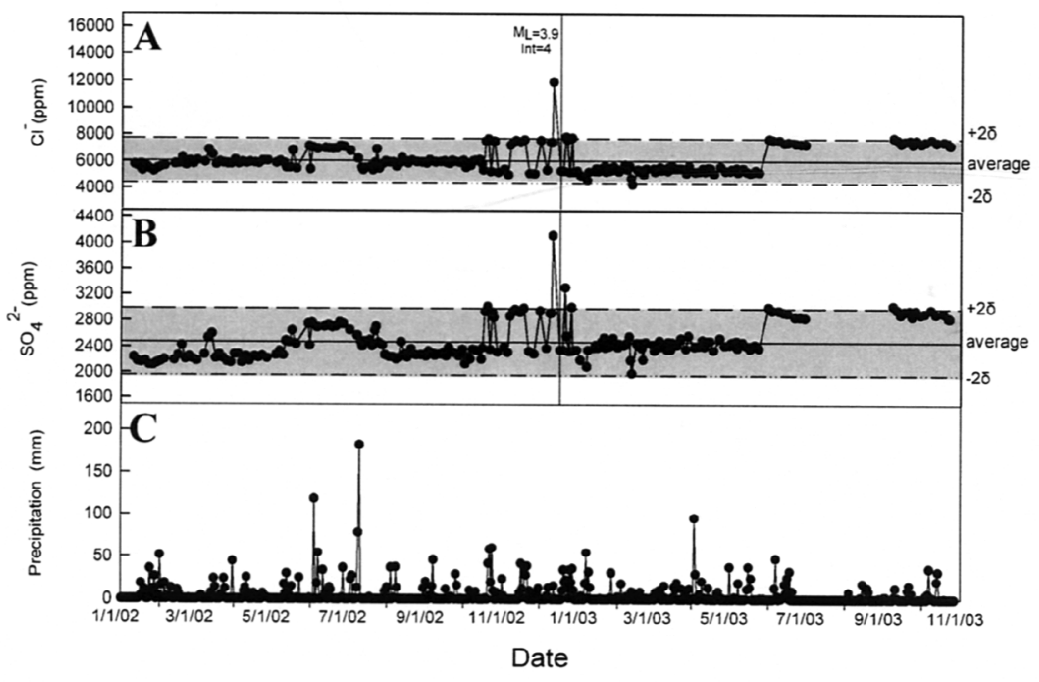

Fig. 5. Temporal variations of (A) $\mathrm{Cl}^{-}$and (B) $\mathrm{SO}_{4}{ }^{2-}$ concentrations in the Tapu hot spring. The vertical lines represent the same as Fig. 2. (C) Daily precipitation record is the same as Fig. 3.

epicenter of the earthquake that likely induced the two chemical anomalies was the same as one of those at the Chingshan hot springs and was located in northeast Taiwan (Fig. 7).

Again, the chloride and sulfate ions are also the major anions in the Yuanshan hot spring, and their average concentration reaches $56.0 \pm 17.3 \mathrm{ppm}$ and $6.95 \pm 1.25 \mathrm{ppm}$, respectively. The two-sigma relative standard deviation $(2 \sigma)$ is $30.9 \%\left(\mathrm{Cl}^{-}\right)$and $18.0 \%\left(\mathrm{SO}_{4}{ }^{2-}\right)$. In general, the respective concentration in the sets of samples of each is almost constant, except during two periods (Figs. 6A, B). Two chloride anomalies and one sulfate anomaly is detected in the Yuanshan hot springs. They occur around May 18 and September 30, 2003 for chloride, and September 26, 2003 for sulfate, for an approximate duration of a few days each. Both epicenters of the earthquakes that must have induced the chemical anomalies were predominantly located very near the monitoring site in the Ilan Plain of northeast Taiwan (Fig. 7). 


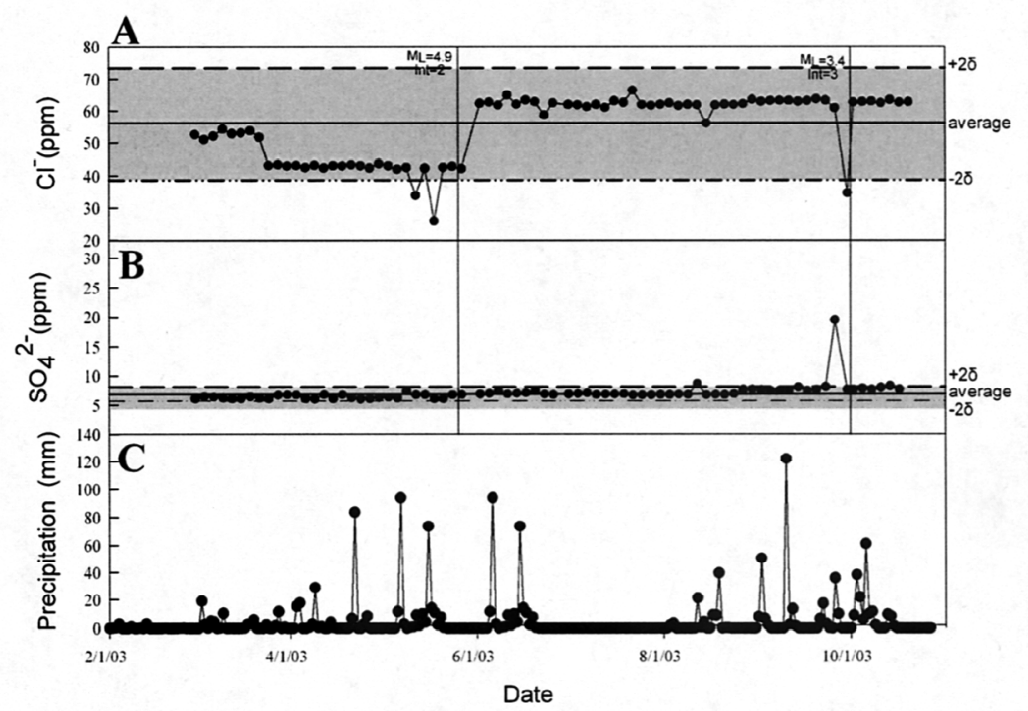

Fig. 6. Temporal variations of (A) $\mathrm{Cl}^{-}$and (B) $\mathrm{SO}_{4}{ }^{2-}$ concentrations in the Yuangshan hot spring. The vertical lines represent the same as Fig. 2. (C) Daily precipitation recorded in the Ilan rain gauge station (data from the CWBT).

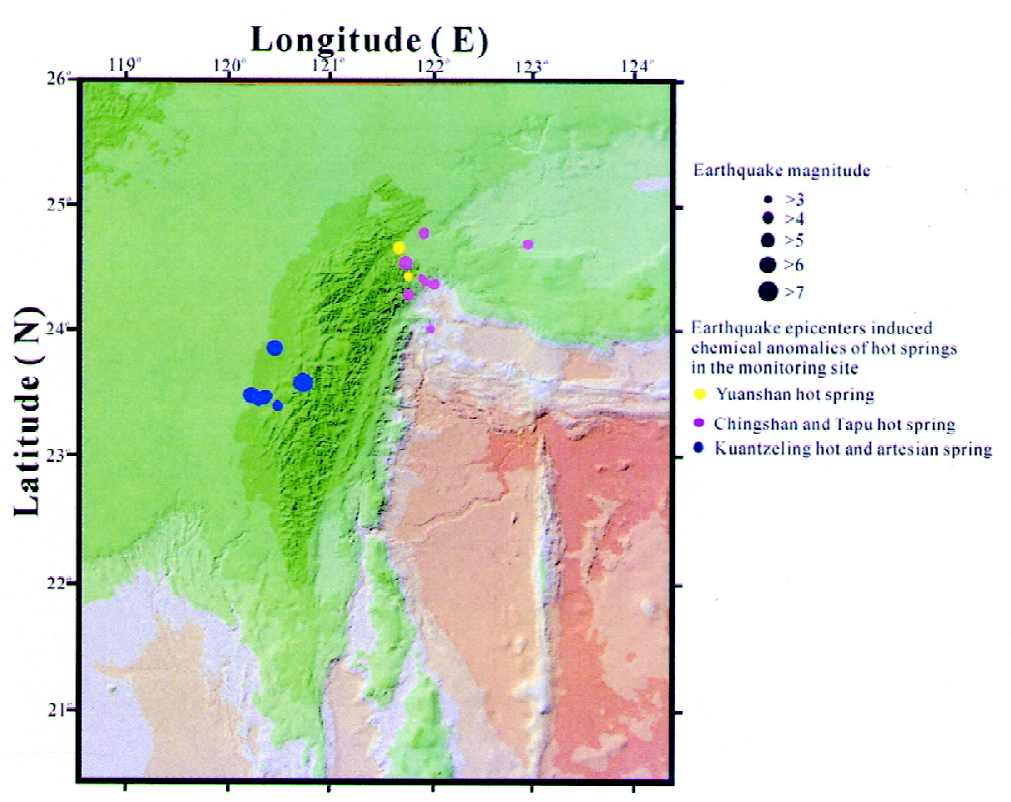

Fig. 7. Distribution of earthquake epicenters which induced the hydrochemical anomalies in the springs at the monitoring sites. 


\subsection{Artesian Spring}

One artesian spring, the Kuantzeling, was chosen for regular sampling in this study of earthquake precursors. Temporal variations in the concentration of $\mathrm{Cl}^{-}$and $\mathrm{SO}_{4}{ }^{2-}$ in the water samples in the January 2000 to September 2001 period are shown in Figs. 8A, B, respectively. Here, the sulfate ion is the major anion in the spring water, with an average concentration of $25.4 \pm 4.5 \mathrm{ppm}$ compared with an average concentration of $2.70 \pm 0.82 \mathrm{ppm}$ for the chloride ion (Table 2). The chloride and sulfate concentrations are fairly constant in all samples during the sampling periods. Similarly, the $2 \sigma$ relative standard deviation is $30.4 \%\left(\mathrm{Cl}^{-}\right)$and $17.9 \%$ $\left(\mathrm{SO}_{4}{ }^{2-}\right)$. In essence, these $2 \sigma$ domains can be taken as representative of the spring water background values, and they may be attributed to annual fluctuations in groundwater chemistry, changes which are mainly a consequence of rainfall, other superficial phenomena, heterogeneity in the sampling and analytical uncertainties (Toutain et al. 1997). Except for the chloride and sulfate ions, all of the cations and anions vary within the $2 \sigma$ domains throughout all of the sampling periods. Figure 8 shows that given the sharp increases in the three periods, the $\mathrm{Cl}^{-}$ and $\mathrm{SO}_{4}{ }^{2-}$ concentrations do indeed have anomalies. The anomalies occur almost simultaneously for both elements around April 12 - 15, June 10 - 13 and July 16 of 2000 for durations of just a few to ten days. The epicenters of the earthquakes that probably induced the chemical anomalies were same as those at the Kuantzeling hot springs and were predominantly located in central Taiwan very near the monitoring site (Fig. 7). The exception is the epicenter of the earthquake of July 16, 2000 which located in offshore SE Taiwan (Table 1).

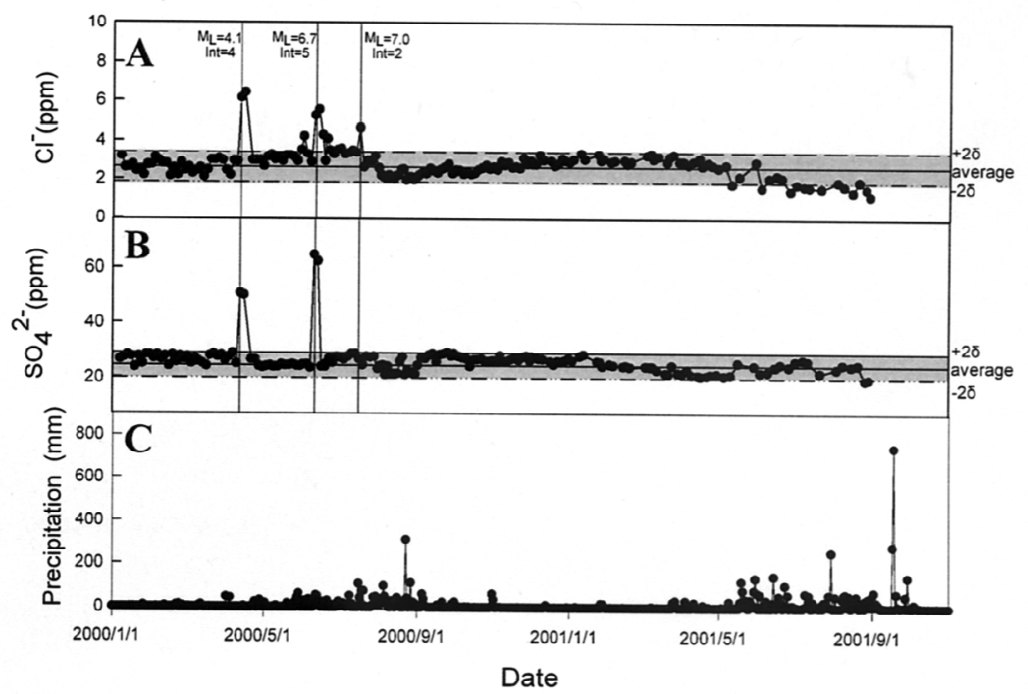

Fig. 8. Temporal variations of (A) $\mathrm{Cl}^{-}$and (B) $\mathrm{SO}_{4}{ }^{2-}$ concentrations in the Kuantzeling artesian spring. The vertical lines represent the same with Fig. 2. (C) Daily precipitation record is the same as Fig. 2. 


\subsection{Groundwater}

Four sites with groundwater were chosen for regular sampling to evaluate their potential for the monitoring of earthquake precursors. They are located in Meinong, Tashu and Chaochou in southwest Taiwan, and Yuanshan in the northeast. Their depths range from several tens to $250 \mathrm{~m}$. Sampling periods for each site was one year.

Temporal variations in the $\mathrm{Cl}^{-}$and $\mathrm{SO}_{4}{ }^{2-}$ concentrations in the water samples from these four groundwater sites are shown in Figs. 9 - 12, respectively. The average concentration and the two-sigma relative standard deviation $(2 \sigma)$ were calculated and are also plotted in the same figures and listed in Table 2 . The $2 \sigma$ domains can be taken as representative of the groundwater background values which may be considered the product of annual fluctuations in groundwater chemistry, these mainly being a consequence of rainfall, other superficial phenomena, heterogeneity in the sampling and analytical uncertainties (Toutain et al. 1997).

The sulfate ion with average concentrations of $80.8 \pm 17.3 \mathrm{ppm}, 58.5 \pm 10.1 \mathrm{ppm}$ and $48.9 \pm 4.1 \mathrm{ppm}$ in the Meinong, Tashu and Chaochou groundwater, respectively, is the major anion; this compares with the average concentrations of $11.4 \pm 1.8 \mathrm{ppm}, 13.6 \pm 2.5 \mathrm{ppm}$ and $2.8 \pm 0.6 \mathrm{ppm}$ for the chloride ion in the same water samples. The $2 \sigma$ relative standard deviation is $15.8 \%\left(\mathrm{Cl}^{-}\right)$and $21.4 \%\left(\mathrm{SO}_{4}{ }^{2-}\right)$ for the Meinong groundwater, $18.4 \%\left(\mathrm{Cl}^{-}\right)$and $17.3 \%$ $\left(\mathrm{SO}_{4}{ }^{2-}\right)$ for the Tashu groundwater and $21.4 \%\left(\mathrm{Cl}^{-}\right)$and $8.4 \%\left(\mathrm{SO}_{4}{ }^{2-}\right)$ for the Chaochou groundwater.

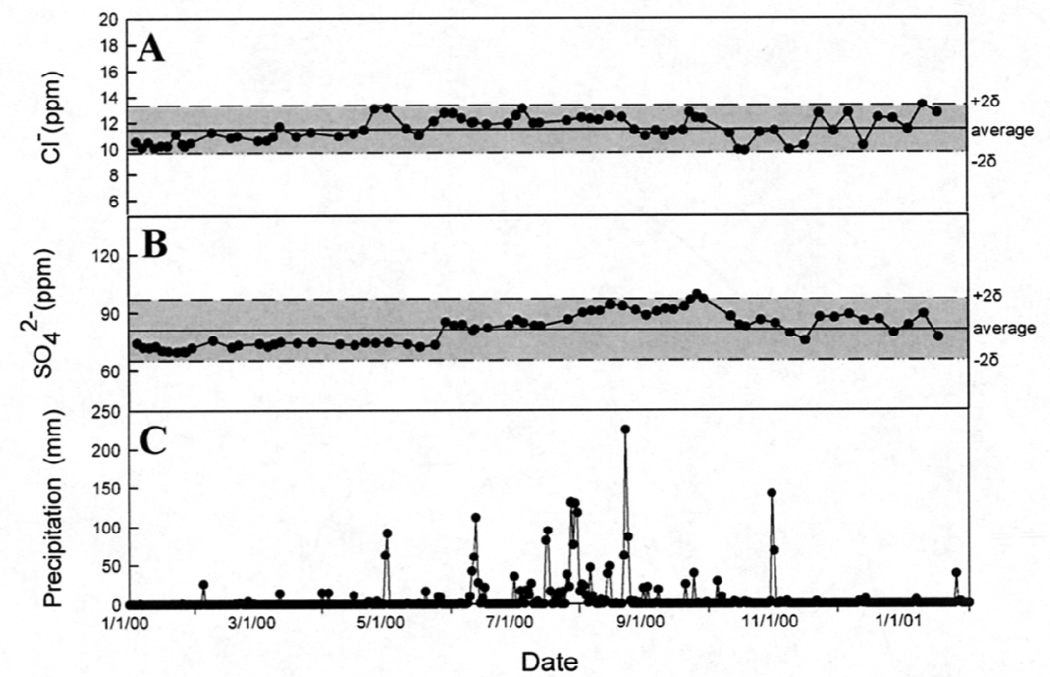

Fig. 9. Temporal variations of (A) $\mathrm{Cl}^{-}$and (B) $\mathrm{SO}_{4}{ }^{2-}$ concentrations in the Meinong groundwater. (C) Daily precipitation recorded in the Chaochou rain gauge station (data from the CWBT). 


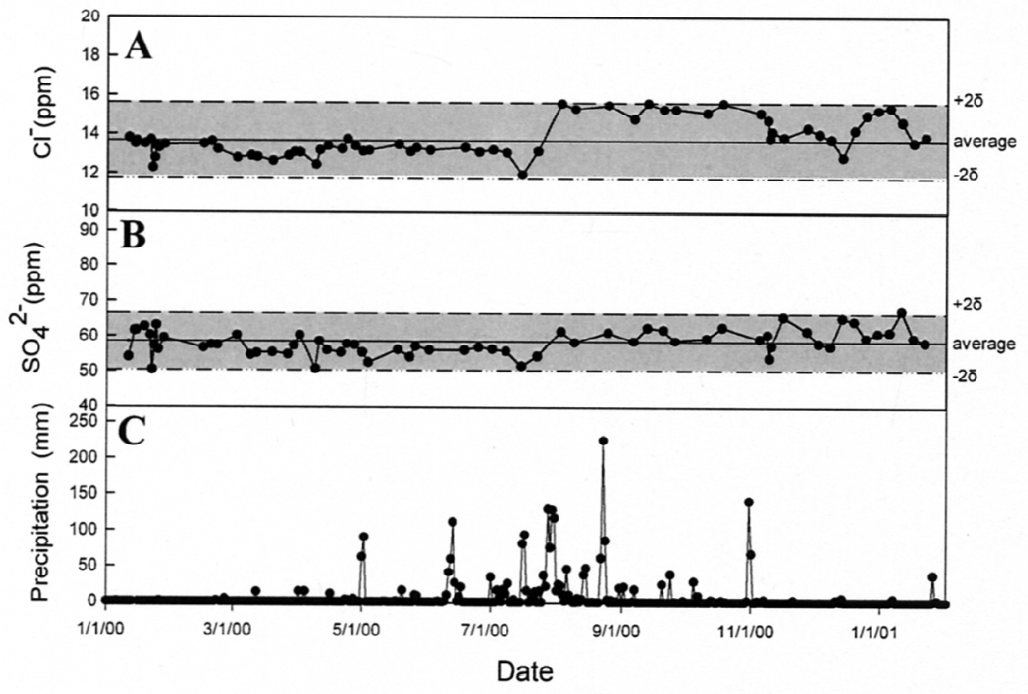

Fig. 10. Temporal variations of (A) $\mathrm{Cl}^{-}$and (B) $\mathrm{SO}_{4}{ }^{2-}$ concentrations in the Tashu groundwater. (C) Daily precipitation record is the same as Fig. 9.

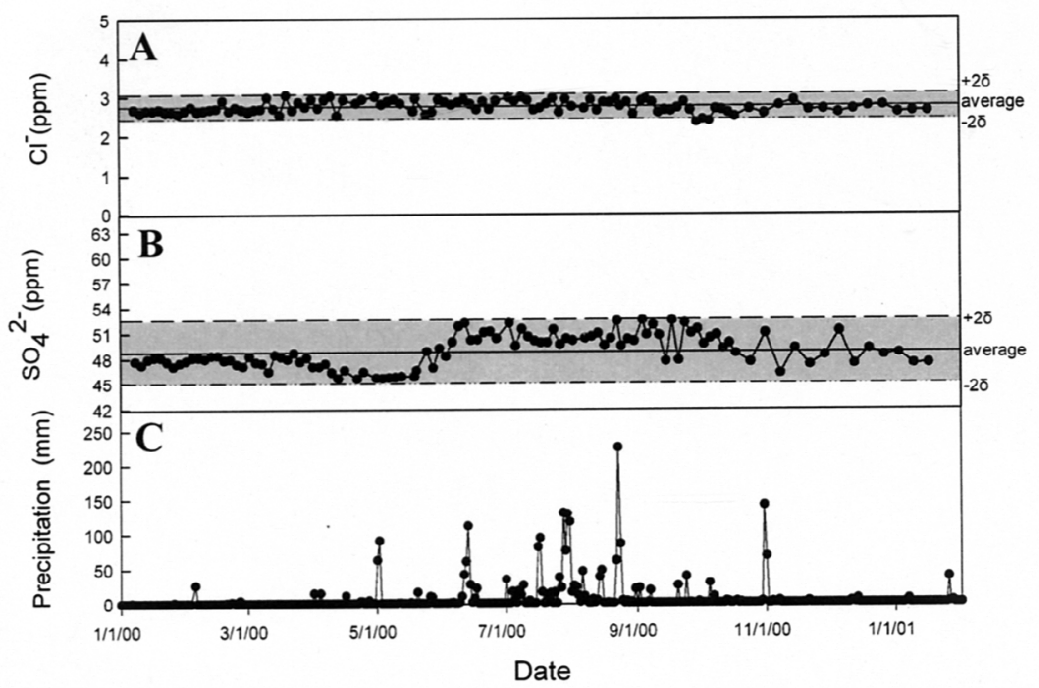

Fig. 11. Temporal variations of (A) $\mathrm{Cl}^{-}$and (B) $\mathrm{SO}_{4}{ }^{2-}$ concentrations in the Chaochou groundwater. (C) Daily precipitation record is the same as Fig. 9. 
Turning to Yuanshan in the northeast, the respective concentration of the chloride and sulfate ions in groundwater is low at $3.73 \pm 2.66$ and $16.0 \pm 2.7 \mathrm{ppm}$, and the $2 \sigma$ relative standard deviation is $71.3 \%\left(\mathrm{Cl}^{-}\right)$and $16.9 \%\left(\mathrm{SO}_{4}{ }^{2-}\right)$.

In all four of these groundwater sites, the concentration of $\mathrm{Cl}^{-}$and that of $\mathrm{SO}_{4}{ }^{2-}$ in all of the samples is fairly constant, though there are variations in the $2 \sigma$ domains throughout the sampling periods (Figs. 9 - 12). All other cations and anions also vary within the $2 \sigma$ domains during the same periods.

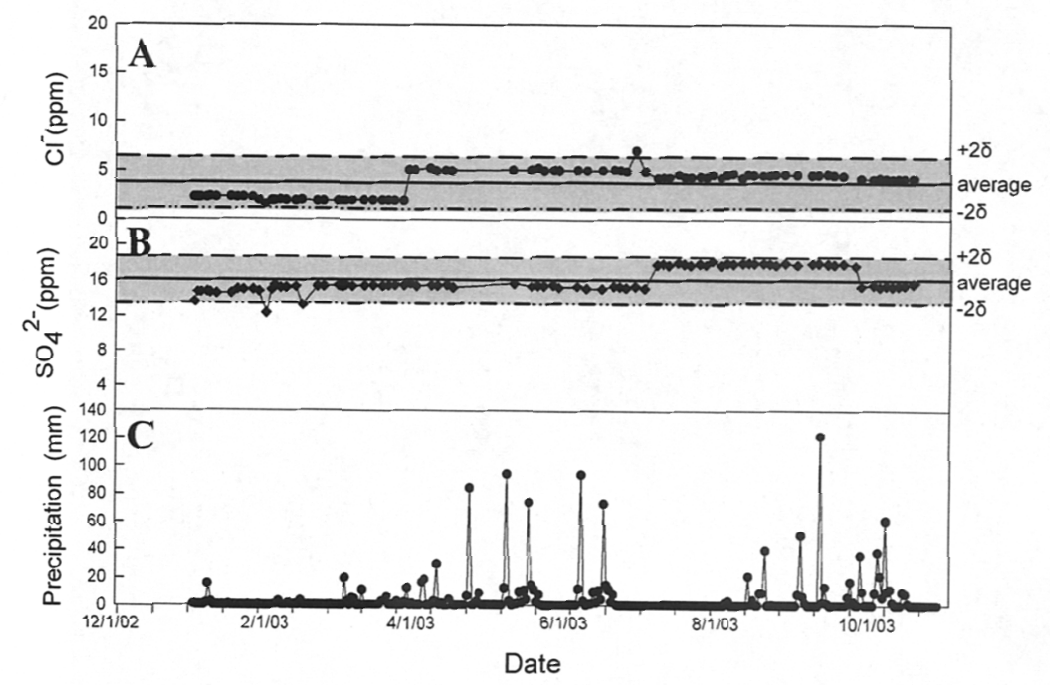

Fig. 12. Temporal variations of (A) $\mathrm{Cl}^{-}$and (B) $\mathrm{SO}_{4}{ }^{2-}$ concentrations in the Yuanshan groundwater. (C) Daily precipitation record is the same as Fig. 6.

\section{DISCUSSIONS}

The respective chemical composition of the hot springs and artesian spring and groundwater do indeed tend to change, and this can be attributed to several factors. These include, but are not limited to, varying compositions of groundwater recharge, water-rock interactions (Domenico and Schwartz 1990; Langmuir 1997), the mixing of different water compositions and artificial pollutants. Among all of the factors capable of causing the observed temporal variations in the concentrations $\mathrm{Cl}^{-}$and $\mathrm{SO}_{4}{ }^{2-}$ for relatively short durations (Figs. 2 - 6 and 8), the mixing of different water compositions (King et al. 1981; Thomas 1988) and artificial pollutants are the only two that cannot flatly be ruled out. Most of the monitoring sites are located in industry-free, sparsely populated countryside or mountainous areas. Besides this, a medium, like meteoric water, is required to carry pollutant solutes down into the subsurface water system. However, lacking here is any evidence of correlated relationships among the anomalies of the ions in the temporal variations and in the daily amounts of precipitation 
throughout the entire sampling period (Figs. 2 - 6 and 8). Pertinent here are the results of the analysis of tritium $\left({ }^{3} \mathrm{H}\right)$, where it is clear that the concentration of ${ }^{3} \mathrm{H}$ in the hot springs is less than $0.2 \mathrm{TU}$ (tritium unit) (Liu, unpublished data), strongly suggesting that the hot springs came from older subsurface water bodies, the ages of which may be well over 50 years. This observation is a strong sign that the observed temporal variations in the $\mathrm{Cl}^{-}$and $\mathrm{SO}_{4}{ }^{2-}$ concentrations have not, in fact, been induced by recent meteoric water flowing down into the circulation system of the subsurface water system. On the weight of this evidence, it is reasonable to conclude that the abrupt changes we witness in the temporal variations in the $\mathrm{Cl}^{-}$and $\mathrm{SO}_{4}{ }^{2-}$ concentrations cannot be attributed to artifact pollutants.

The mixing of different water compositions in a subsurface water body can be induced in three ways: by the mixing of meteoric and formation waters, the mixing of groundwater and brines or pore waters, and by the mixing of different aquifers or reservoirs with different chemical compositions (Domenico and Schwartz 1990). Of these, the first two processes may gradually change the temporary chemical composition of water and eventually result in a permanent change, or at least a change that lasts a considerably long period of time; with the third process, although the mixing of different aquifers or reservoirs with different chemical compositions can quickly occur, the chemical changes more than likely disappear within a relatively short period of time. Figures $2-6$ and 8 clearly illustrate that the chemical changes in these springs are abrupt and that the dates correlate well with the occurrence of earthquakes. Thus, it seems justifiable to attribute the factor that causes the rapid temporal chemical variations in the hot springs and the artesian spring and in the groundwater at these monitoring sites to the mixing of different aquifers or reservoirs. It should be equally reasonable to make the claim that the factors which led to the rapid temporal chemical variations must have been induced by those earthquakes.

Worth bearing in mind, the steps that take place during an earthquake cycle are fivefold: 1) strain accumulation; 2) the occurrence of micro-cracks; 3) fluid injection; 4) the occurrence of an earthquake; and 5) a drop in stress (Bolt 1999). The mixing of two individual subsurface water bodies occurs in steps 2 and 3 of the earthquake cycle. More to the point, the chemical compositions of subsurface water systems are normally quite stable, but when the monitoring of a reservoir shows chemical anomalies from mixing, there should, of course, be different chemical compositions among these subsurface water bodies. Based on the temporal variations shown in the water composition of ten monitoring sites (Figs. 2 - 6, 8 - 12), all of the hot springs as well as the artesian spring showed chemical anomalies which could serve as earthquake precursors in certain periods. However, the groundwater clearly did not (Figs. 9 - 12).

A hot spring is composed of thermal water which circulates from the deep. Well known from silica geothermometry is that the silica temperature $\left(\mathrm{T}_{\mathrm{SiO}_{2}}\right)$ of most hot springs that have been monitored is over $100^{\circ} \mathrm{C}$ (Song et al., unpublished data), and taking the geothermal gradient as $30-50^{\circ} \mathrm{C} \mathrm{km}^{-1}$ in Taiwan (Lee and Cheng 1986), this indicates that hot springs come from a subsurface reservoir which is at least more than $2 \mathrm{~km}$ deep. And yet, because there are probably many shallow reservoirs with different chemical compositions above the hot springs, these shallow reservoirs have more opportunity to mix with other reservoirs with different compositions as they circulate upward to the surface during step 2 in the earthquake 
process when micro-cracks occur before an earthquake. For this vary reason, the fact that all of the hot springs at the monitoring sites show chemical anomalies in response to earthquake events cab be explained.

Artesian springs and groundwater are in saturated zones and circulate in the shallow which is derived from rainfall and infiltration within the normal hydrological cycle. The Kuantzeling artesian spring is located in fine-grained rocks, shale or siltstones of the Tertiary sedimentary rocks in the Western foothills. Based on regional geology and the usage patterns of local people, the reservoir of this spring is small, and the permeability is also low, which means the chemicals are easily affected by water percolating from other reservoirs with different compositions. It would not be surprising, therefore, that in the present study, several anomalies are identified as earthquake precursors during the monitoring periods. However, the Meinong, Tashu and Chaochou groundwater sites are located on the Pintung Plain which is a fluvial apron predominantly composed of gravels with sandy and silty layers. Accordingly, the reservoirs of groundwater in the area of the Pintung Plain are very large, and the permeability may be also high, highly indicative that the chemicals were not significantly affected by mixing from other reservoirs with different compositions. Thus, the temporal variations in these three monitoring sites were quite stable and did not appear to have responded in any way to any earthquake events.

The correlations between the earthquake epicenters and chemical anomalous events in the springs of the Kuantzeling, Chingshan and Yuanshan areas show that the seismic events induced fluid mixing in the subsurface water systems and that this occurred in very restricted regions (Fig. 7). The monitoring sites - for example, those located in the Chiayi area- were only affected by the earthquakes that occurred in central Taiwan. In contrast, those located in the Chingshan and Ilan areas were only affected by the earthquakes that occurred in northeast Taiwan. Taiwan is located within the complexity of the oblique collision zone of the Eurasian continental plate and the Philippine oceanic plate. Presently, rapid crustal movement and widely distributed active structures are the geological characteristics of this young tectonic entity ( $\mathrm{Yu}$ et al. 1997, 1999; Chang et al. 1998). Hence, in terms of tectonic activity, seven and four neotectonic domains, respectively, can be identified in western and eastern Taiwan, and what's more, each domain is bound by its own distinct active structure (Shyu et al. 2005). Beyond this, each may have its own response to stress accumulation and faulting. This active structural complexity may very well be the dominant factor that controls the hydrochemical changes which are, with no doubt, in response to earthquakes, thus attesting to their capability to serve as earthquake precursors at monitoring sites. However, the results from this study can not explain why the duration changes of chemical anomaly responding to earthquakes in the same monitoring site are different and why some earthquakes induce chemical anomalies in subsurface water body, but some don't (Figs. 2 - 6 and 8). It needs further studies in collecting more data to statistically analyze.

\section{CONCLUSIONS}

Located as it is in an orogenic belt with highly active seismicity, Taiwan has often been 
struck by major devastating earthquakes, such as the 1999 Chi-Chi earthquake, which caused a huge number of fatalities as well as the destruction of countless buildings. Nonetheless, this has also given rise to numerous opportunities to investigate potential hydrological monitoring sites which might serve as geochemical precursors of earthquakes in Taiwan. Ten subsurface water bodies in southwestern, northern and northeastern Taiwan were chosen to evaluate the best working sites and the most useful ions for monitoring earthquake precursors in different tectonic domains. The results are convincing: the factors strictly controlling the chemical anomalies that are considered as precursors of an earthquake in subsurface waters are the kinds, the depths and the size of a reservoir as well as the ion species of the water body. Hot springs from deeper zones are, by far, superior to artesian springs and groundwater from shallower reservoirs. Artesian springs from smaller water bodies are also superior to groundwater from larger reservoirs. The anion, especially chloride, is substantially a better precursor than is the cation.

Acknowledgements The authors would like to thank many research assistants and students for their assistance with field sampling and the partial IC and ICP-AES analyses. Thanks are also due to two referees and Dr. C. Y. Lan whose suggestions and valuable reviews greatly improved the manuscript. This research was supported by the Central Geological Survey, Ministry of Economic Affairs and partly by the National Science Council, Republic of China under grants NSC 91-2116-M-002-020 and 92-2116-M-002-014.

\section{REFERENCES}

Barsukov, V. L., G. M. Varshal, and N. S. Zamokina, 1984/1985: Recent results of hydrogeochemical studies for earthquake prediction in the USSR.Pure Appl. Geophys., 122, 143-156.

Bolt, B. A., 1999: Earthquakes. W. H. Freeman and Company, New York, 331 pp.

Chang, H. C., C. W. Lin, M. M. Chen, and S. T. Lu, 1998: An introduction to the active faults of Taiwan: Explanatory text for the active fault of Taiwan, scale 1:500000. Spec. publ. Cent. Geol. Surv., Taiwan. 10, 103 pp. (In Chinese with English abstract)

Central Weather Bureau of Taiwan, 2004: CWBT climate and earthquake report.http://www. cwb.gov.tw/V4/index.htm/climate data.

Chyi, L. L., T. J. Quick, T. F. Yang, and C. H. Chen, 2005: Soil gas radon spectra and earthquakes. Terr. Atmos. Ocean. Sci., 16, 763-774.

Claesson, L., A. Skelton, C. Graham, C. Dietl, M. Morth, P. Torssander, and I. Kockum, 2004: Hydrogeochemical changes before and after a major earthquake. Geology, 32, 641-644.

Chung, J. K., and T. C. Shin, 1999: Implications of the rupture process from the displacement distribution of strong ground motions recorded during the 21 September 1999 Chi-Chi Taiwan earthquake. Terr. Atmos. Ocean. Sci., 10, 777-786.

Domenico, P. A. and F. W. Schwartz, 1990: Physical and chemical hydrogeology. John Wiley $\&$ Sons, Singapore, $824 \mathrm{pp}$. 
Guiru, L., W. Fongliang, W. Jihua, and Z. Peiren, 1984/1985: Preliminary results of seismogeochemical research in China. Pure Appl. Geophys., 122, 218-230.

Hauksson, E., 1981: Radon contents of groundwater as an earthquake precursor: evaluation of worldwide data and physical basis. J. Geophys. Res., 86, 9397-9410.

Ho, C. S. 1986: An introduction to the geology of Taiwan: Explanatory text of the geologic map of Taiwan. Cent. Geol. Surv., Taiwan, 163 pp.

Italiano, F., A. Caracausi, R. Favara, P. Innocenzi, and G. Martinelli, 2005: Geochemical monitoring of cold waters during seismicity: Implications for earthquake-induced modification in shallow aquifers. Terr. Atmos. Ocean. Sci., 16, 709-729.

Kao, H., and W. P. Chen, 2000: The Chi-Chi earthquake sequence: active out-of-sequence thrust faulting in Taiwan. Science, 288, 2346-2349.

King, C. Y. 1986: Gas geochemistry applied to earthquake prediction. An overview, $J$. Geophys. Res., 91, 12269-12281.

King, C. Y., Evans, W. C., Presser, T., and Husk, R., 1981: Anomalous chemical changes in well waters and possible relation to earthquakes. Geophys. Res. Lett., 8, 425-428.

Koizumi, N., R. Yoshioka, and Y. Kishimoto, 1985: Earthquake prediction by means of change of chemical composition in mineral spring water. Geophys. Res. Lett., 12, 510-513.

Langmuir, D., 1997: Aqueous environmental geochemistry. Prentice-Hall, New Jersey, 540 pp.

Lee, C. R., and W. T. Cheng, 1986: Preliminary heat flow measurements in Taiwan. Abs. Fourth Circum-Pacific Energy Mineral Res. Conf., Singapore.

Muir-Wood, R., and G. C. P. King, 1993: Hydrological signatures of earthquake strain.J. Geophys. Res., 98, 22035-22068.

Ramirez-Guzman, A., Y. A. Taran, R. Bernard, E. Cienfuegos, and P. Morales, 2005: Variations in the $\mathrm{Cl}, \mathrm{SO}_{4}, \delta \mathrm{D}$ and $\delta{ }^{18} \mathrm{O}$ in water from thermal springs near Acapulco, Guerrero, Mexico, related to seismic activity. Terr. Atmos. Ocean. Sci., 16, 731-743.

Rojstaczer, S., and S. Wolf, 1992: Permeability changes associated with large earthquakes: an example from Loma Prieta, California. Geology, 20, 211-214.

Rojstaczer, S., S. Wolf, and R. Michel, 1995: Permeability enhancement in the shallow crust as a cause of earthquake-induced hydrological changes. Nature, 373, 237-239.

Satake, H., M. Murata, and H. Hayashi, 2002: Chemical characteristics of groundwater around the Mozumbi-Sukenobu fault and the implication for fault activity. Geophy. Res. Lett., 29, 1-4.

Shyu, J. B. H., K. Sieh, Y. G. Chen, and C. S. Liu, 2005: The neotectonic architecture of Taiwan and its implications for future large earthquakes.J. Geophy. Res., 110, B08402, doi:10.1029/2004JB003251.

Song, S. R., W. Y. Ku, Y. L. Chen, I. C. Lin. C. M. Liu, L. W. Kuo, T. F. Yang, and H. J. Lo, 2003: Groundwater chemical anomaly before and after the Chi-Chi Earthquake in Taiwan. Terr. Atmos. Ocean. Sci., 14, 311-320.

Song, S. R., W. Y. Ku, Y. L. Chen, W. Y. Yu, C. M. Liu, Y. G. Chen, T. F. Yang, C. H. Chen, T. K. Liu, and M. Lee, 2005: Hydrogeochemical anomaly in springs in the Chaiyi area, southern Taiwan and its possible relation to earthquakes. Pure Appl. Geophys.. (in review)

Sugisaki, R., K. Ito, K. Nagamine, and I. Kawabe, 1996: Gas geochemical changes at mineral springs associated with the 1995 southern Hyogo earthquake $(\mathrm{M}=7.2)$, Japan. Earth Planet. Sci. Lett., 139, 239-249. 
Thomas, D. 1988: Geochemical precursors to seismic activity. Pure Appl. Geophys., 126, 241-265.

Toutain, J. P., M. Munoz, F. Poitrasson, and A. C. Lienard, 1997: Springwater chloride ion anomaly prior to a $\mathrm{M}_{\mathrm{L}}=5.2$ Pyrenean earthquake. Earth Planet. Sci. Lett., 149, 113119.

Tsunogai, U., and H. Wakita, 1995: Precursory chemical changes in ground water: Kobe earthquake, Japan. Science, 269, 61-63.

Tsunogai, U., and H. Wakita, 1996: Anomalous change in groundwater chemistry- possible precursors of the 1995 Hyogo-ken Nanbu Earthquake, Japan. J. Phys. Earth, 44, 381390.

Walia, V., H. S. Virk, T. F. Yang, S. Mahajan, M. Walia, and B. S. Bajwa, 2005: Earthquake prediction studies using radon as a precursor in $\mathrm{N}-\mathrm{W}$ Himalayas, India: A case study. Terr. Atmos. Ocean. Sci., 16, 775-804.

Yang, T. F., V. Walia, L. L. Chyi, C. C. Fu, C. H. Chen, T. K. Liu, S. R. Song, C. Y. Lee, and M. Lee, 2005: Variations of soil radon and thoron concentrations in a fault zone and prospective earthquakes in SW Taiwan. Radiat. Meas., 40, 496-502.

Yu, S. B., H. Y. Chen, and L. C. Kuo, 1997: Velociety field of GPS stations in the Taiwan area. Tectonophy., 274, 41-59.

Yu, S. B., L. C. Kuo, R. S. Punongbayan, and E. G. Ramos, 1999: GPS observation of crystal deformation in the Taiwan-Luzon region. Geophys. Res. Lett., 26, 923-926. 
Appendix 1: The $\mathrm{Cl}^{-}$and $\mathrm{SO}_{4}{ }^{2-}$ concentrations (ppm) of the Kuantzeling hot spring

\begin{tabular}{|c|c|c|c|c|c|c|c|c|}
\hline Date & $\mathrm{Cl}^{-}$ & $\mathrm{SO}_{4}{ }^{2-}$ & Date & $\mathrm{Cl}^{-}$ & $\mathrm{SO}_{4}{ }^{2-}$ & Date & $\mathrm{Cl}^{-}$ & $\mathrm{SO}_{4}{ }^{2-}$ \\
\hline 7/15/1999 & 2093 & 28.1 & 11/8/1999 & 2200 & 11.8 & 2/19/2000 & 2132 & 46.6 \\
\hline 8/8/1999 & 1983 & 21.7 & 11/9/1999 & 2233 & 20.5 & $2 / 22 / 2000$ & 2272 & 72.8 \\
\hline 8/18/1999 & 1875 & 23.5 & 11/10/1999 & 2193 & 44.5 & $2 / 25 / 2000$ & 2102 & 45.7 \\
\hline 8/20/1999 & 2123 & 25.4 & 11/11/1999 & 2237 & 40.3 & $2 / 28 / 2000$ & 2123 & 31.1 \\
\hline 8/27/1999 & 2178 & 25.8 & 11/12/1999 & 2043 & 41.0 & $3 / 1 / 2000$ & 2385 & 80.3 \\
\hline 9/3/1999 & 2219 & 23.7 & 11/13/1999 & 2242 & 40.5 & $3 / 2 / 2000$ & 2272 & 78.6 \\
\hline 9/12/1999 & 2153 & 14.1 & 11/14/1999 & 2054 & 27.5 & $3 / 5 / 2000$ & 2055 & 63.6 \\
\hline 9/14/1999 & 2215 & 24.7 & 11/15/1999 & 2263 & 41.0 & $3 / 8 / 2000$ & 2141 & 48.2 \\
\hline 9/19/1999 & 2970 & 11.7 & 11/16/1999 & 2388 & 39.9 & $3 / 11 / 2000$ & 2057 & 59.0 \\
\hline 9/26/1999 & 2268 & 34.1 & 11/17/1999 & 2406 & 37.7 & $3 / 17 / 2000$ & 1994 & 40.3 \\
\hline 10/1/1999 & 2988 & 13.5 & 11/18/1999 & 2260 & 31.9 & $3 / 20 / 2000$ & 2022 & 38.1 \\
\hline 10/11/1999 & 2284 & 34.4 & 11/19/1999 & 2259 & 38.0 & $3 / 23 / 2000$ & 2089 & 84.6 \\
\hline 10/12/1999 & 2306 & 34.6 & 11/20/1999 & 2425 & 33.1 & $3 / 26 / 2000$ & 2133 & 38.3 \\
\hline 10/13/1999 & 2287 & 35.5 & 11/21/1999 & 2237 & 33.2 & $3 / 29 / 2000$ & 2220 & 41.3 \\
\hline 10/14/1999 & 2285 & 33.9 & 11/22/1999 & 2382 & 35.6 & $4 / 1 / 2000$ & 2258 & 83.8 \\
\hline 10/15/1999 & 2136 & 33.8 & 11/23/1999 & 2145 & 30.7 & $4 / 4 / 2000$ & 2359 & 126.6 \\
\hline 10/16/1999 & 2234 & 29.3 & 11/24/1999 & 2226 & 32.5 & $4 / 7 / 2000$ & 2398 & 119.7 \\
\hline 10/17/1999 & 2184 & 28.3 & 11/25/1999 & 2000 & 32.9 & $4 / 10 / 2000$ & 2320 & 38.8 \\
\hline 10/18/1999 & 2236 & 34.8 & 11/26/1999 & 2112 & 33.7 & $4 / 13 / 2000$ & 2266 & 38.1 \\
\hline 10/19/1999 & 2211 & 35.4 & 11/27/1999 & 2263 & 27.5 & $4 / 16 / 2000$ & 1764 & 88.4 \\
\hline 10/20/1999 & 2593 & 29.8 & $1 / 6 / 2000$ & 2388 & 41.0 & $4 / 19 / 2000$ & 2168 & 67.2 \\
\hline 10/21/1999 & 2635 & 39.4 & $1 / 9 / 2000$ & 2406 & 39.9 & $4 / 25 / 2000$ & 2196 & 44.8 \\
\hline 10/22/1999 & 2646 & 39.9 & $1 / 12 / 2000$ & 2260 & 44.5 & $4 / 28 / 2000$ & 2164 & 36.5 \\
\hline 10/24/1999 & 2399 & 38.6 & $1 / 15 / 2000$ & 2259 & 27.4 & $5 / 1 / 2000$ & 2340 & 61.7 \\
\hline 10/25/1999 & 2627 & 47.4 & $1 / 18 / 2000$ & 2085 & 38.0 & $5 / 4 / 2000$ & 1714 & 65.3 \\
\hline 10/26/1999 & 2489 & 43.8 & $1 / 21 / 2000$ & 2177 & 33.1 & $5 / 7 / 2000$ & 2299 & 55.0 \\
\hline 10/27/1999 & 2585 & 40.8 & $1 / 24 / 2000$ & 2123 & 20.3 & $5 / 10 / 2000$ & 2534 & 48.6 \\
\hline 10/28/1999 & 2361 & 37.5 & $1 / 27 / 2000$ & 2200 & 35.6 & $5 / 13 / 2000$ & 2485 & 17.9 \\
\hline 10/29/1999 & 2497 & 40.9 & $1 / 29 / 2000$ & 2150 & 30.7 & $5 / 16 / 2000$ & 2413 & 43.0 \\
\hline 10/30/1999 & 2553 & 39.1 & $2 / 1 / 2000$ & 2150 & 32.5 & $5 / 19 / 2000$ & 2426 & 20.6 \\
\hline 10/31/1999 & 3107 & 32.4 & $2 / 4 / 2000$ & 2204 & 32.9 & $5 / 25 / 2000$ & 2464 & 36.1 \\
\hline 11/4/1999 & 2617 & 36.5 & $2 / 7 / 2000$ & 2177 & 33.7 & $5 / 28 / 2000$ & 2183 & 33.8 \\
\hline 11/5/1999 & 1851 & 49.6 & $2 / 10 / 2000$ & 2166 & 40.6 & $5 / 31 / 2000$ & 2317 & 37.0 \\
\hline 11/6/1999 & 2623 & 36.5 & $2 / 13 / 2000$ & 2188 & 32.5 & $6 / 3 / 2000$ & 2290 & 34.3 \\
\hline 11/7/1999 & 2558 & 36.4 & $2 / 17 / 2000$ & 2080 & 48.1 & $6 / 6 / 2000$ & 2306 & 21.8 \\
\hline
\end{tabular}




\begin{tabular}{|c|c|c|c|c|c|c|c|c|}
\hline 6/9/2000 & 1886 & 49.7 & $10 / 20 / 2000$ & 2334 & 40.7 & $3 / 4 / 2001$ & 2243 & 30.6 \\
\hline $6 / 12 / 2000$ & 2299 & 33.9 & $10 / 23 / 2000$ & 2266 & 62.4 & 3/7/2001 & 2262 & 57.6 \\
\hline $6 / 15 / 2000$ & 2306 & 34.5 & $10 / 26 / 2000$ & 2380 & 29.3 & 3/10/2001 & 2314 & 41.0 \\
\hline 6/18/2000 & 2313 & 36.0 & $10 / 29 / 2000$ & 2987 & 18.0 & 3/13/2001 & 2300 & 24.7 \\
\hline 6/20/2000 & 2311 & 36.3 & $11 / 1 / 2000$ & 2437 & 42.9 & $3 / 21 / 2001$ & 2376 & 36.6 \\
\hline $6 / 21 / 2000$ & 2312 & 44.1 & $11 / 4 / 2000$ & 2734 & 20.7 & 3/27/2001 & 2620 & 35.7 \\
\hline $6 / 24 / 2000$ & 2321 & 36.5 & $11 / 7 / 2000$ & 2461 & 35.7 & 3/30/2001 & 2295 & 54.2 \\
\hline 6/30/2000 & 2329 & 34.9 & $11 / 10 / 2000$ & 2291 & 15.9 & $4 / 2 / 2001$ & 2022 & 36.1 \\
\hline $7 / 6 / 2000$ & 2345 & 35.7 & $11 / 13 / 2000$ & 2304 & 37.4 & 4/8/2001 & 2173 & 42.4 \\
\hline $7 / 9 / 2000$ & 2339 & 35.5 & $11 / 16 / 2000$ & 2373 & 20.7 & 4/14/2001 & 2289 & 39.9 \\
\hline $7 / 12 / 2000$ & 2361 & 36.9 & $11 / 19 / 2000$ & 2342 & 26.2 & 4/17/2001 & 2385 & 30.5 \\
\hline 7/18/2000 & 2366 & 36.5 & $11 / 22 / 2000$ & 2444 & 26.2 & 4/20/2001 & 2259 & 38.6 \\
\hline $7 / 21 / 2000$ & 2386 & 35.3 & $11 / 25 / 2000$ & 2388 & 79.3 & 4/23/2001 & 2108 & 16.9 \\
\hline $7 / 24 / 2000$ & 2418 & 36.9 & $11 / 28 / 2000$ & 2259 & 53.9 & $4 / 26 / 2001$ & 2171 & 34.8 \\
\hline $8 / 2 / 2000$ & 2365 & 36.2 & $12 / 1 / 2000$ & 2449 & 39.2 & 4/29/2001 & 2189 & 43.8 \\
\hline $8 / 5 / 2000$ & 2305 & 37.5 & $12 / 4 / 2000$ & 2361 & 73.0 & $5 / 2 / 2001$ & 2363 & 39.6 \\
\hline $8 / 8 / 2000$ & 2382 & 39.1 & $12 / 7 / 2000$ & 2365 & 28.2 & 5/9/2001 & 1997 & 24.4 \\
\hline $8 / 11 / 2000$ & 2299 & 38.7 & $12 / 10 / 2000$ & 2249 & 59.6 & $5 / 18 / 2001$ & 2216 & 6.5 \\
\hline $8 / 14 / 2000$ & 2188 & 40.3 & $12 / 13 / 2000$ & 2269 & 33.3 & $6 / 2 / 2001$ & 1786 & 5.4 \\
\hline 8/17/2000 & 2307 & 38.3 & $12 / 16 / 2000$ & 2310 & 14.0 & $6 / 11 / 2001$ & 2001 & 24.2 \\
\hline 8/20/2000 & 2542 & 37.9 & $12 / 19 / 2000$ & 2196 & 54.5 & $6 / 17 / 2001$ & 2006 & 22.4 \\
\hline 8/23/2000 & 2508 & 34.9 & $12 / 22 / 2000$ & 2219 & 32.3 & 6/23/2001 & 2140 & 42.2 \\
\hline $8 / 26 / 2000$ & 2538 & 35.6 & $12 / 25 / 2000$ & 2310 & 59.3 & $6 / 29 / 2001$ & 2034 & 67.5 \\
\hline 8/30/2000 & 2406 & 35.2 & $12 / 31 / 2000$ & 2091 & 74.4 & $7 / 2 / 2001$ & 2256 & 20.7 \\
\hline $9 / 4 / 2000$ & 2329 & 37.2 & $1 / 3 / 2001$ & 2123 & 54.1 & 7/11/2001 & 2367 & 52.3 \\
\hline $9 / 7 / 2000$ & 2320 & 37.7 & $1 / 6 / 2001$ & 2365 & 58.1 & 7/17/2001 & 2372 & 54.9 \\
\hline 9/10/2000 & 2267 & 34.4 & $1 / 9 / 2001$ & 2051 & 51.4 & 7/23/2001 & 1974 & 24.6 \\
\hline 9/13/2000 & 2222 & 33.3 & $1 / 12 / 2001$ & 2184 & 50.9 & 7/29/2001 & 2491 & 17.7 \\
\hline 9/17/2000 & 2182 & 35.5 & $1 / 15 / 2001$ & 2323 & 59.9 & 8/1/2001 & 2522 & 22.4 \\
\hline 9/20/2000 & 2212 & 34.4 & $1 / 18 / 2001$ & 2466 & 73.1 & & & \\
\hline 9/26/2000 & 2231 & 33.4 & $1 / 21 / 2001$ & 2421 & 111.8 & & & \\
\hline 9/29/2000 & 2225 & 33.7 & $1 / 27 / 2001$ & 2518 & 102.9 & & & \\
\hline $10 / 2 / 2000$ & 2178 & 34.9 & $2 / 2 / 2001$ & 2319 & 55.9 & & & \\
\hline $10 / 5 / 2000$ & 1904 & 32.3 & $2 / 4 / 2001$ & 1900 & 28.0 & & & \\
\hline $10 / 8 / 2000$ & 2486 & 31.8 & 2/5/2001 & 2331 & 38.4 & & & \\
\hline $10 / 11 / 2000$ & 2346 & 32.4 & 2/17/2001 & 2324 & 63.6 & & & \\
\hline $10 / 14 / 2000$ & 2460 & 30.4 & 2/20/2001 & 2451 & 31.5 & & & \\
\hline $10 / 17 / 2000$ & 2023 & 40.4 & 2/26/2001 & 2297 & 29.9 & & & \\
\hline
\end{tabular}


Appendix 2: The $\mathrm{Cl}^{-}$and $\mathrm{SO}_{4}{ }^{2-}$ concentrations (ppm) of the Chingshan hot spring (50 m)

\begin{tabular}{|c|c|c|c|c|c|c|c|c|}
\hline Date & $\mathrm{Cl}^{-}$ & $\mathrm{SO}_{4}{ }^{2-}$ & Date & $\mathrm{Cl}^{-}$ & $\mathrm{SO}_{4}{ }^{2-}$ & Date & $\mathrm{Cl}^{-}$ & $\mathrm{SO}_{4}{ }^{2-}$ \\
\hline 1/11/2002 & 621.9 & 191.4 & $5 / 21 / 2002$ & 647.8 & 200.6 & 9/18/2002 & 601.0 & 188.5 \\
\hline $1 / 15 / 2002$ & 620.2 & 188.8 & $5 / 24 / 2002$ & 600.9 & 169.8 & 9/20/2002 & 608.0 & 191.1 \\
\hline 1/18/2002 & 619.2 & 190.1 & 5/29/2002 & 618.8 & 191.9 & $9 / 25 / 2002$ & 605.7 & 188.3 \\
\hline $1 / 22 / 2002$ & 617.3 & 187.9 & 5/31/2002 & 630.1 & 195.8 & 9/27/2002 & 603.2 & 189.5 \\
\hline $1 / 25 / 2002$ & 621.5 & 195.0 & $6 / 5 / 2002$ & 637.1 & 198.5 & $10 / 1 / 2002$ & 605.7 & 189.0 \\
\hline 1/29/2002 & 616.5 & 189.9 & 6/8/2002 & 625.4 & 195.0 & $10 / 3 / 2002$ & 602.8 & 183.8 \\
\hline 2/1/2002 & 620.8 & 197.6 & $6 / 12 / 2002$ & 638.8 & 198.5 & 10/6/2002 & 606.5 & 190.5 \\
\hline 2/5/2002 & 618.7 & 189.4 & $6 / 14 / 2002$ & 617.6 & 192.7 & $10 / 8 / 2002$ & 604.1 & 188.1 \\
\hline 2/8/2002 & 615.1 & 187.2 & 6/16/2002 & 611.0 & 185.9 & $10 / 12 / 2002$ & 599.7 & 186.3 \\
\hline 2/13/2002 & 618.2 & 194.9 & $6 / 18 / 2002$ & 618.5 & 192.5 & $10 / 15 / 2002$ & 603.3 & 189.8 \\
\hline 2/19/2002 & 619.2 & 192.8 & $6 / 21 / 2002$ & 620.7 & 194.1 & $10 / 18 / 2002$ & 632.9 & 189.6 \\
\hline 2/22/2002 & 621.8 & 198.2 & $6 / 25 / 2002$ & 626.7 & 196.3 & $10 / 25 / 2002$ & 632.0 & 189.4 \\
\hline $2 / 27 / 2002$ & 614.7 & 192.2 & $6 / 28 / 2002$ & 624.6 & 195.0 & $10 / 28 / 2002$ & 626.7 & 178.9 \\
\hline 3/1/2002 & 620.1 & 194.2 & $7 / 2 / 2002$ & 624.8 & 195.9 & $11 / 1 / 2002$ & 624.4 & 179.2 \\
\hline 3/4/2002 & 603.2 & 176.2 & $7 / 5 / 2002$ & 628.2 & 196.3 & $11 / 4 / 2002$ & 641.0 & 192.0 \\
\hline 3/9/2002 & 614.6 & 189.8 & 7/9/2002 & 621.1 & 195.1 & $11 / 8 / 2002$ & 639.7 & 190.4 \\
\hline 3/15/2002 & 614.6 & 190.2 & 7/13/2002 & 616.2 & 193.7 & $11 / 12 / 2002$ & 641.3 & 193.2 \\
\hline $3 / 19 / 2002$ & 616.0 & 195.8 & 7/17/2002 & 631.4 & 199.3 & $11 / 16 / 2002$ & 633.4 & 190.2 \\
\hline 3/22/2002 & 614.9 & 191.6 & 7/21/2002 & 627.3 & 196.4 & 11/19/2002 & 639.5 & 192.0 \\
\hline 3/26/2002 & 615.3 & 189.9 & 7/23/2002 & 618.5 & 194.5 & 11/21/2002 & 635.0 & 189.8 \\
\hline 3/29/2002 & 596.7 & 174.2 & 7/26/2002 & 603.5 & 190.3 & $11 / 25 / 2002$ & 636.8 & 190.0 \\
\hline $4 / 2 / 2002$ & 617.5 & 192.0 & 7/30/2002 & 603.2 & 188.2 & $11 / 28 / 2002$ & 635.6 & 189.7 \\
\hline $4 / 5 / 2002$ & 614.8 & 191.6 & $8 / 2 / 2002$ & 601.0 & 187.8 & $12 / 2 / 2002$ & 635.9 & 190.2 \\
\hline 4/9/2002 & 615.7 & 194.1 & 8/6/2002 & 603.2 & 189.9 & $12 / 6 / 2002$ & 638.4 & 191.5 \\
\hline 4/12/2002 & 602.8 & 186.7 & 8/9/2002 & 602.2 & 188.3 & $12 / 9 / 2002$ & 629.1 & 177.9 \\
\hline 4/16/2002 & 607.7 & 188.7 & $8 / 13 / 2002$ & 608.8 & 191.7 & $12 / 13 / 2002$ & 644.0 & 192.0 \\
\hline 4/19/2002 & 594.4 & 184.5 & $8 / 16 / 2002$ & 606.2 & 192.0 & $12 / 17 / 2002$ & 642.5 & 200.2 \\
\hline 4/23/2002 & 612.3 & 191.7 & $8 / 22 / 2002$ & 601.6 & 188.5 & $12 / 21 / 2002$ & 640.8 & 191.6 \\
\hline 4/27/2002 & 594.2 & 172.6 & $8 / 24 / 2002$ & 597.1 & 185.9 & $12 / 24 / 2002$ & 639.8 & 192.0 \\
\hline 4/30/2002 & 605.8 & 186.2 & $8 / 27 / 2002$ & 604.6 & 190.2 & $12 / 27 / 2002$ & 642.0 & 192.2 \\
\hline $5 / 3 / 2002$ & 609.5 & 192.6 & 8/30/2002 & 593.2 & 176.7 & $1 / 1 / 2003$ & 617.0 & 194.8 \\
\hline 5/7/2002 & 604.9 & 189.8 & $9 / 4 / 2002$ & 601.4 & 188.0 & $1 / 4 / 2003$ & 614.7 & 195.5 \\
\hline $5 / 10 / 2002$ & 597.9 & 184.7 & 9/6/2002 & 600.6 & 188.8 & $1 / 7 / 2003$ & 614.7 & 189.2 \\
\hline $5 / 16 / 2002$ & 626.6 & 192.7 & $9 / 9 / 2002$ & 600.3 & 186.7 & $1 / 10 / 2003$ & 603.2 & 190.6 \\
\hline $5 / 19 / 2002$ & 630.9 & 198.0 & 9/13/2002 & 588.5 & 181.8 & $1 / 14 / 2003$ & 610.6 & 192.0 \\
\hline
\end{tabular}




\begin{tabular}{|c|c|c|c|c|c|c|c|c|}
\hline 1/17/2003 & 613.4 & 192.4 & 5/23/2003 & 611.0 & 187.2 & 9/30/2003 & 633.4 & 170.9 \\
\hline $1 / 24 / 2003$ & 606.0 & 191.8 & $6 / 2 / 2003$ & 626.4 & 164.6 & $10 / 4 / 2003$ & 668.3 & 163.1 \\
\hline $1 / 27 / 2003$ & 603.1 & 193.1 & 6/6/2003 & 599.9 & 164.9 & $10 / 7 / 2003$ & 649.2 & 171.5 \\
\hline 2/1/2003 & 597.7 & 180.4 & $6 / 10 / 2003$ & 627.4 & 165.0 & $10 / 11 / 2003$ & 629.5 & 156.4 \\
\hline 2/3/2003 & 608.8 & 194.2 & $6 / 13 / 2003$ & 634.2 & 177.8 & $10 / 14 / 2003$ & 642.5 & 173.2 \\
\hline 2/7/2003 & 614.1 & 194.2 & $6 / 16 / 2003$ & 631.3 & 182.9 & $10 / 21 / 2003$ & 639.4 & 171.6 \\
\hline 2/11/2003 & 615.5 & 193.5 & $6 / 20 / 2003$ & 629.2 & 175.4 & $10 / 23 / 2003$ & 636.9 & 171.9 \\
\hline 2/14/2003 & 615.2 & 194.1 & $6 / 23 / 2003$ & 627.0 & 174.6 & & & \\
\hline 2/17/2003 & 614.1 & 192.2 & $6 / 27 / 2003$ & 633.1 & 179.5 & & & \\
\hline $2 / 21 / 2003$ & 601.1 & 191.6 & $6 / 30 / 2003$ & 628.7 & 175.1 & & & \\
\hline 3/6/2003 & 599.4 & 192.3 & $7 / 4 / 2003$ & 630.2 & 168.9 & & & \\
\hline 3/10/2003 & 603.4 & 193.1 & $7 / 7 / 2003$ & 631.0 & 170.2 & & & \\
\hline $3 / 14 / 2003$ & 601.0 & 192.6 & $7 / 11 / 2003$ & 628.7 & 169.8 & & & \\
\hline 3/19/2003 & 589.2 & 177.5 & 7/23/2003 & 631.1 & 170.8 & & & \\
\hline $3 / 25 / 2003$ & 600.9 & 191.8 & $7 / 26 / 2003$ & 629.6 & 170.5 & & & \\
\hline 3/31/2003 & 592.4 & 175.0 & 7/29/2003 & 627.2 & 169.9 & & & \\
\hline 4/4/2003 & 610.8 & 195.1 & 8/1/2003 & 627.0 & 168.1 & & & \\
\hline 4/7/2003 & 611.4 & 193.2 & 8/5/2003 & 622.8 & 166.0 & & & \\
\hline 4/11/2003 & 610.6 & 192.8 & 8/9/2003 & 627.4 & 171.0 & & & \\
\hline $4 / 14 / 2003$ & 607.6 & 193.5 & $8 / 11 / 2003$ & 627.7 & 168.8 & & & \\
\hline 4/18/2003 & 614.5 & 196.8 & $8 / 15 / 2003$ & 627.2 & 169.4 & & & \\
\hline $4 / 22 / 2003$ & 593.7 & 155.4 & $8 / 22 / 2003$ & 624.2 & 168.0 & & & \\
\hline $4 / 25 / 2003$ & 605.8 & 186.0 & $8 / 27 / 2003$ & 623.1 & 166.8 & & & \\
\hline 4/28/2003 & 619.4 & 189.4 & 9/3/2003 & 625.2 & 167.3 & & & \\
\hline 5/1/2003 & 618.1 & 189.1 & 9/5/2003 & 625.6 & 128.7 & & & \\
\hline $5 / 5 / 2003$ & 613.6 & 189.4 & 9/9/2003 & 624.3 & 165.3 & & & \\
\hline 5/9/2003 & 618.2 & 190.1 & 9/12/2003 & 626.3 & 168.8 & & & \\
\hline $5 / 12 / 2003$ & 634.5 & 190.1 & 9/16/2003 & 633.0 & 171.5 & & & \\
\hline 5/16/2003 & 618.9 & 190.2 & $9 / 20 / 2003$ & 630.1 & 169.6 & & & \\
\hline 5/19/2003 & 621.7 & 190.4 & $9 / 24 / 2003$ & 631.2 & 170.5 & & & \\
\hline
\end{tabular}


Appendix 3: The $\mathrm{Cl}^{-}$and $\mathrm{SO}_{4}{ }^{2-}$ concentrations (ppm) of the Chingshan hot spring (100 m)

\begin{tabular}{|c|c|c|c|c|c|c|c|c|}
\hline Date & $\mathrm{Cl}^{-}$ & $\mathrm{SO}_{4}{ }^{2-}$ & Date & $\mathrm{Cl}^{-}$ & $\mathrm{SO}_{4}{ }^{2-}$ & Date & $\mathrm{Cl}^{-}$ & $\mathrm{SO}_{4}{ }^{2-}$ \\
\hline $1 / 11 / 2002$ & 275.7 & 68.7 & $5 / 21 / 2002$ & 340.0 & 42.8 & $9 / 18 / 2002$ & 251.9 & 63.2 \\
\hline 1/15/2002 & 295.5 & 72.7 & $5 / 24 / 2002$ & 344.5 & 70.0 & 9/20/2002 & 319.0 & 76.1 \\
\hline 1/18/2002 & 272.8 & 68.0 & $5 / 29 / 2002$ & 344.0 & 69.5 & $9 / 25 / 2002$ & 265.1 & 65.9 \\
\hline $1 / 22 / 2002$ & 266.8 & 70.4 & 5/31/2002 & 345.8 & 69.5 & 9/27/2002 & 326.7 & 76.8 \\
\hline $1 / 25 / 2002$ & 311.3 & 78.4 & $6 / 5 / 2002$ & 361.9 & 71.7 & $10 / 1 / 2002$ & 324.1 & 77.1 \\
\hline 1/29/2002 & 258.7 & 67.1 & 6/8/2002 & 365.6 & 71.3 & $10 / 3 / 2002$ & 313.3 & 74.3 \\
\hline 2/1/2002 & 258.3 & 67.5 & $6 / 12 / 2002$ & 355.6 & 69.6 & $10 / 6 / 2002$ & 329.8 & 77.7 \\
\hline 2/5/2002 & 258.3 & 65.7 & $6 / 14 / 2002$ & 362.7 & 74.8 & $10 / 8 / 2002$ & 329.0 & 77.2 \\
\hline 2/8/2002 & 260.0 & 67.4 & 6/16/2002 & 357.5 & 74.8 & $10 / 12 / 2002$ & 343.9 & 74.4 \\
\hline 2/13/2002 & 272.0 & 69.5 & $6 / 18 / 2002$ & 355.9 & 74.7 & $10 / 15 / 2002$ & 690.9 & 79.4 \\
\hline 2/19/2002 & 252.3 & 65.8 & $6 / 21 / 2002$ & 361.5 & 75.0 & 10/18/2002 & 298.2 & 67.9 \\
\hline 2/22/2002 & 340.2 & 83.2 & $6 / 25 / 2002$ & 359.0 & 74.9 & $10 / 25 / 2002$ & 378.2 & 83.2 \\
\hline 2/27/2002 & 275.5 & 70.8 & $6 / 28 / 2002$ & 342.3 & 73.3 & $10 / 28 / 2002$ & 345.3 & 75.1 \\
\hline 3/1/2002 & 396.3 & 70.2 & $7 / 2 / 2002$ & 362.5 & 75.0 & $11 / 1 / 2002$ & 26.8 & 64.6 \\
\hline 3/4/2002 & 238.6 & 64.3 & 7/5/2002 & 345.4 & 68.4 & $11 / 4 / 2002$ & 270.4 & 64.8 \\
\hline 3/9/2002 & 392.1 & 99.9 & 7/9/2002 & 350.1 & 68.9 & $11 / 8 / 2002$ & 286.0 & 58.2 \\
\hline $3 / 15 / 2002$ & 268.9 & 67.5 & 7/13/2002 & 357.4 & 69.5 & $11 / 12 / 2002$ & 278.5 & 65.4 \\
\hline 3/19/2002 & 270.4 & 63.8 & 7/17/2002 & 342.5 & 67.5 & $11 / 16 / 2002$ & 492.5 & 73.4 \\
\hline 3/22/2002 & 272.5 & 66.0 & 7/21/2002 & 278.9 & 69.1 & 11/19/2002 & 267.4 & 64.7 \\
\hline 3/26/2002 & 276.4 & 69.4 & $7 / 23 / 2002$ & 332.0 & 77.0 & $11 / 21 / 2002$ & 265.7 & 64.2 \\
\hline 3/29/2002 & 278.0 & 69.4 & 7/26/2002 & 322.2 & 75.4 & $11 / 25 / 2002$ & 431.7 & 92.6 \\
\hline 4/2/2002 & 268.1 & 66.5 & 7/30/2002 & 327.4 & 76.7 & $11 / 28 / 2002$ & 456.4 & 100.4 \\
\hline 4/5/2002 & 267.0 & 40.7 & $8 / 2 / 2002$ & 330.4 & 76.9 & $12 / 2 / 2002$ & 339.7 & 76.3 \\
\hline 4/9/2002 & 267.2 & 66.6 & 8/6/2002 & 300.4 & 72.9 & $12 / 6 / 2002$ & 297.8 & 68.5 \\
\hline 4/12/2002 & 320.1 & 82.7 & $8 / 9 / 2002$ & 295.0 & 71.5 & $12 / 9 / 2002$ & 852.8 & 243.4 \\
\hline 4/16/2002 & 247.0 & 70.4 & $8 / 13 / 2002$ & 317.4 & 75.3 & $12 / 13 / 2002$ & 339.2 & 73.6 \\
\hline 4/19/2002 & 222.2 & 63.9 & $8 / 16 / 2002$ & 317.9 & 74.9 & 12/17/2002 & 312.5 & 70.9 \\
\hline 4/23/2002 & 240.0 & 67.6 & $8 / 22 / 2002$ & 318.2 & 75.2 & $12 / 21 / 2002$ & 362.7 & 78.3 \\
\hline 4/27/2002 & 325.6 & 78.1 & $8 / 24 / 2002$ & 247.0 & 62.8 & $12 / 24 / 2002$ & 386.3 & 79.2 \\
\hline 4/30/2002 & 335.1 & 77.9 & $8 / 27 / 2002$ & 241.9 & 62.3 & $12 / 27 / 2002$ & 312.8 & 70.1 \\
\hline 5/3/2002 & 316.9 & 73.5 & 8/30/2002 & 255.0 & 63.9 & $1 / 1 / 2003$ & 335.2 & 75.4 \\
\hline 5/7/2002 & 342.0 & 70.0 & 9/4/2002 & 253.8 & 64.2 & $1 / 4 / 2003$ & 234.0 & 56.0 \\
\hline 5/10/2002 & 336.3 & 68.8 & 9/6/2002 & 250.3 & 63.1 & $1 / 7 / 2003$ & 440.6 & 108.5 \\
\hline $5 / 16 / 2002$ & 352.2 & 70.6 & 9/9/2002 & 483.9 & 65.1 & $1 / 10 / 2003$ & 427.9 & 104.5 \\
\hline 5/19/2002 & 301.8 & 64.5 & 9/13/2002 & 258.3 & 64.7 & $1 / 14 / 2003$ & 242.4 & 56.4 \\
\hline
\end{tabular}




\begin{tabular}{|c|c|c|c|c|c|c|c|c|}
\hline $1 / 17 / 2003$ & 312.8 & 73.0 & 5/16/2003 & 302.1 & 69.5 & 9/20/2003 & 279.8 & 70.2 \\
\hline $1 / 24 / 2003$ & 302.9 & 67.5 & $5 / 19 / 2003$ & 289.3 & 67.1 & $9 / 24 / 2003$ & 236.8 & 65.3 \\
\hline $1 / 27 / 2003$ & 249.8 & 58.1 & 5/23/2003 & 280.5 & 66.5 & 9/30/2003 & 297.8 & 72.4 \\
\hline 2/1/2003 & 270.5 & 62.5 & $6 / 2 / 2003$ & 284.6 & 71.0 & $10 / 4 / 2003$ & 304.0 & 73.9 \\
\hline $2 / 3 / 2003$ & 236.0 & 55.7 & $6 / 6 / 2003$ & 279.6 & 68.9 & $10 / 7 / 2003$ & 300.3 & 73.9 \\
\hline 2/7/2003 & 424.3 & 98.5 & 6/10/2003 & 262.2 & 67.3 & $10 / 11 / 2003$ & 283.7 & 70.7 \\
\hline 2/14/2003 & 248.4 & 57.7 & $6 / 13 / 2003$ & 281.0 & 73.5 & $10 / 14 / 2003$ & 290.4 & 76.2 \\
\hline 2/17/2003 & 269.0 & 62.1 & $6 / 16 / 2003$ & 286.5 & 69.8 & $10 / 21 / 2003$ & 283.3 & 70.7 \\
\hline 2/21/2003 & 364.0 & 92.0 & $6 / 20 / 2003$ & 244.6 & 66.9 & $10 / 23 / 2003$ & 274.0 & 69.1 \\
\hline 2/24/2003 & 293.1 & 68.0 & $6 / 23 / 2003$ & 281.9 & 71.3 & & & \\
\hline 2/28/2003 & 275.3 & 62.4 & 6/27/2003 & 300.8 & 78.8 & & & \\
\hline 3/6/2003 & 240.4 & 56.6 & 6/30/2003 & 308.8 & 74.3 & & & \\
\hline 3/10/2003 & 254.2 & 60.2 & $7 / 4 / 2003$ & 296.4 & 68.7 & & & \\
\hline 3/14/2003 & 249.7 & 57.0 & $7 / 7 / 2003$ & 296.1 & 73.3 & & & \\
\hline 3/19/2003 & 339.8 & 79.6 & $7 / 11 / 2003$ & 302.7 & 73.9 & & & \\
\hline $3 / 25 / 2003$ & 214.2 & 56.3 & $7 / 23 / 2003$ & 296.6 & 72.4 & & & \\
\hline 3/28/2003 & 661.4 & 172.6 & 7/26/2003 & 284.5 & 70.8 & & & \\
\hline $3 / 31 / 2003$ & 396.7 & 91.9 & $7 / 29 / 2003$ & 298.4 & 72.4 & & & \\
\hline 4/4/2003 & 231.2 & 58.8 & 8/1/2003 & 306.9 & 74.2 & & & \\
\hline 4/7/2003 & 365.0 & 89.6 & 8/5/2003 & 281.7 & 79.4 & & & \\
\hline 4/11/2003 & 287.0 & 66.6 & 8/9/2003 & 293.2 & 71.8 & & & \\
\hline 4/14/2003 & 448.2 & 103.2 & $8 / 11 / 2003$ & 303.8 & 73.4 & & & \\
\hline 4/18/2003 & 290.8 & 67.7 & $8 / 15 / 2003$ & 300.2 & 72.2 & & & \\
\hline $4 / 22 / 2003$ & 327.0 & 85.0 & $8 / 22 / 2003$ & 206.6 & 56.5 & & & \\
\hline 4/25/2003 & 251.4 & 71.2 & $8 / 27 / 2003$ & 293.4 & 71.6 & & & \\
\hline 4/28/2003 & 286.6 & 78.0 & 9/3/2003 & 309.0 & 74.4 & & & \\
\hline $5 / 1 / 2003$ & 263.5 & 64.4 & $9 / 5 / 2003$ & 295.2 & 73.4 & & & \\
\hline 5/5/2003 & 287.6 & 67.0 & 9/9/2003 & 308.2 & 73.8 & & & \\
\hline 5/9/2003 & 197.0 & 55.9 & $9 / 12 / 2003$ & 304.9 & 74.5 & & & \\
\hline $5 / 12 / 2003$ & 278.7 & 65.8 & 9/16/2003 & 298.2 & 72.4 & & & \\
\hline
\end{tabular}


Appendix 4: The $\mathrm{Cl}^{-}$and $\mathrm{SO}_{4}{ }^{2-}$ concentrations (ppm) of the Tapu hot spring

\begin{tabular}{|c|c|c|c|c|c|c|c|c|}
\hline Date & $\mathrm{Cl}^{-}$ & $\mathrm{SO}_{4}{ }^{2-}$ & Date & $\mathrm{Cl}^{-}$ & $\mathrm{SO}_{4}{ }^{2-}$ & Date & $\mathrm{Cl}^{-}$ & $\mathrm{SO}_{4}^{2-}$ \\
\hline 1/11/2002 & 5793 & 2233 & $5 / 10 / 2002$ & 5904 & 2265 & 8/28/2002 & 5968 & 2275 \\
\hline $1 / 14 / 2002$ & 5646 & 2171 & $5 / 12 / 2002$ & 5553 & 2490 & 8/31/2002 & 5966 & 2281 \\
\hline $1 / 16 / 2002$ & 5823 & 2160 & $5 / 15 / 2002$ & 5556 & 2469 & $9 / 1 / 2002$ & 5890 & 2249 \\
\hline 1/17/2002 & 5348 & 2157 & $5 / 17 / 2002$ & 6833 & 2647 & 9/3/2002 & 6141 & 2334 \\
\hline $1 / 20 / 2002$ & 5685 & 2176 & $5 / 20 / 2002$ & 5487 & 2442 & 9/7/2002 & 6004 & 2297 \\
\hline $1 / 23 / 2002$ & 5447 & 2116 & 5/30/2002 & 7155 & 2746 & 9/8/2002 & 5962 & 2263 \\
\hline $1 / 26 / 2002$ & 5275 & 2108 & $5 / 31 / 2002$ & 5439 & 2424 & $9 / 12 / 2002$ & 6007 & 2286 \\
\hline $1 / 29 / 2002$ & 5487 & 2144 & $6 / 2 / 2002$ & 7062 & 2760 & $9 / 15 / 2002$ & 6044 & 2316 \\
\hline 2/1/2002 & 5613 & 2166 & 6/6/2002 & 6959 & 2693 & 9/17/2002 & 5952 & 2252 \\
\hline 2/4/2002 & 5704 & 2197 & $6 / 12 / 2002$ & 7018 & 2704 & 9/19/2002 & 5879 & 2391 \\
\hline 2/12/2002 & 5841 & 2188 & $6 / 15 / 2002$ & 6983 & 2726 & $9 / 21 / 2002$ & 6095 & 2325 \\
\hline 2/15/2002 & 5863 & 2265 & 6/18/2002 & 6973 & 2700 & 9/23/2002 & 6032 & 2308 \\
\hline 2/18/2002 & 6282 & 2423 & $6 / 21 / 2002$ & 6978 & 2707 & 9/27/2002 & 5966 & 2255 \\
\hline $2 / 21 / 2002$ & 5756 & 2206 & $6 / 24 / 2002$ & 7174 & 2769 & 9/30/2002 & 6098 & 2363 \\
\hline $2 / 24 / 2002$ & 6071 & 2250 & $6 / 27 / 2002$ & 7107 & 2747 & $10 / 2 / 2002$ & 5577 & 2135 \\
\hline 2/27/2002 & 5848 & 2208 & $7 / 2 / 2002$ & 6815 & 2658 & $10 / 4 / 2002$ & 5889 & 2244 \\
\hline 3/2/2002 & 6107 & 2180 & 7/8/2002 & 6231 & 2571 & $10 / 6 / 2002$ & 5745 & 2209 \\
\hline 3/8/2002 & 5977 & 2279 & 7/11/2002 & 5562 & 2484 & $10 / 8 / 2002$ & 6067 & 2363 \\
\hline $3 / 11 / 2002$ & 6877 & 2538 & 7/12/2002 & 5397 & 2412 & 10/10/2002 & 6112 & 2353 \\
\hline $3 / 14 / 2002$ & 6509 & 2601 & $7 / 14 / 2002$ & 5541 & 2478 & $10 / 13 / 2002$ & 6158 & 2343 \\
\hline $3 / 17 / 2002$ & 5811 & 2219 & $7 / 18 / 2002$ & 5622 & 2502 & $10 / 15 / 2002$ & 5858 & 2207 \\
\hline 3/20/2002 & 5985 & 2283 & 7/20/2002 & 5370 & 2415 & $10 / 16 / 2002$ & 5388 & 2385 \\
\hline 3/23/2002 & 5907 & 2217 & $7 / 22 / 2002$ & 5955 & 2643 & $10 / 18 / 2002$ & 7537 & 2939 \\
\hline $3 / 26 / 2002$ & 5857 & 2166 & 7/23/2002 & 6944 & 2702 & $10 / 20 / 2002$ & 7689 & 3015 \\
\hline 3/29/2002 & 5829 & 2150 & 7/25/2002 & 5499 & 2466 & $10 / 22 / 2002$ & 5272 & 2362 \\
\hline 4/1/2002 & 6143 & 2284 & 7/28/2002 & 5866 & 2429 & $10 / 24 / 2002$ & 7537 & 2925 \\
\hline 4/4/2002 & 5849 & 2285 & 7/30/2002 & 6035 & 2275 & $10 / 25 / 2002$ & 7525 & 2845 \\
\hline 4/7/2002 & 5959 & 2150 & $8 / 2 / 2002$ & 5964 & 2246 & $10 / 28 / 2002$ & 5211 & 2319 \\
\hline 4/10/2002 & 5895 & 2251 & 8/5/2002 & 5945 & 2238 & $11 / 2 / 2002$ & 5442 & 2396 \\
\hline 4/13/2002 & 5968 & 2175 & 8/8/2002 & 5651 & 2206 & $11 / 5 / 2002$ & 5024 & 2315 \\
\hline 4/17/2002 & 5920 & 2249 & $8 / 10 / 2002$ & 5906 & 2227 & $11 / 7 / 2002$ & 7261 & 2870 \\
\hline 4/20/2002 & 5872 & 2227 & $8 / 12 / 2002$ & 6304 & 2474 & $11 / 9 / 2002$ & 7443 & 2937 \\
\hline $4 / 23 / 2002$ & 6078 & 2257 & $8 / 15 / 2002$ & 6030 & 2284 & $11 / 11 / 2002$ & 7591 & 2969 \\
\hline 4/27/2002 & 6072 & 2218 & $8 / 17 / 2002$ & 5889 & 2234 & $11 / 15 / 2002$ & 7457 & 2928 \\
\hline $5 / 4 / 2002$ & 5910 & 2270 & $8 / 20 / 2002$ & 6116 & 2372 & $11 / 18 / 2002$ & 7627 & 2991 \\
\hline $5 / 7 / 2002$ & 6038 & 2336 & $8 / 24 / 2002$ & 5982 & 2270 & $11 / 22 / 2002$ & 5141 & 2334 \\
\hline
\end{tabular}




\begin{tabular}{|c|c|c|c|c|c|c|c|c|}
\hline $11 / 26 / 2002$ & 5113 & 2292 & 2/17/2003 & 5335 & 2429 & $5 / 21 / 2003$ & 5377 & 2430 \\
\hline $12 / 1 / 2002$ & 7574 & 2949 & 2/19/2003 & 5380 & 2458 & $5 / 24 / 2003$ & 5231 & 2377 \\
\hline $12 / 6 / 2002$ & 5393 & 2380 & $2 / 20 / 2003$ & 5272 & 2382 & $6 / 1 / 2003$ & 7696 & 3001 \\
\hline $12 / 9 / 2002$ & 7449 & 2913 & 2/21/2003 & 5057 & 2198 & 6/4/2003 & 7601 & 2955 \\
\hline $12 / 10 / 2002$ & 7448 & 2919 & 2/23/2003 & 5489 & 2468 & 6/9/2003 & 7595 & 2953 \\
\hline $12 / 11 / 2002$ & 11928 & 4119 & $3 / 1 / 2003$ & 5487 & 2437 & 6/13/2003 & 7407 & 2924 \\
\hline $12 / 17 / 2002$ & 5344 & 2354 & $3 / 2 / 2003$ & 5279 & 2343 & $6 / 16 / 2003$ & 7455 & 2915 \\
\hline $12 / 19 / 2002$ & 5327 & 2354 & $3 / 6 / 2003$ & 5601 & 2494 & $6 / 22 / 2003$ & 7382 & 2852 \\
\hline $12 / 21 / 2002$ & 7836 & 3307 & $3 / 7 / 2003$ & 5398 & 2402 & $6 / 26 / 2003$ & 7334 & 2852 \\
\hline $12 / 22 / 2002$ & 7631 & 2568 & $3 / 8 / 2003$ & 5494 & 2433 & 6/30/2003 & 7302 & 2840 \\
\hline $12 / 24 / 2002$ & 5229 & 2329 & $3 / 9 / 2003$ & 5429 & 2407 & $9 / 8 / 2003$ & 7788 & 3029 \\
\hline $12 / 26 / 2002$ & 7766 & 3005 & $3 / 12 / 2003$ & 5336 & 2361 & 9/11/2003 & 7639 & 2972 \\
\hline $12 / 27 / 2002$ & 5249 & 2337 & $3 / 13 / 2003$ & 5618 & 2474 & $9 / 14 / 2003$ & 7395 & 2892 \\
\hline $12 / 30 / 2002$ & 5328 & 2355 & $3 / 15 / 2003$ & 5698 & 2361 & 9/17/2003 & 7544 & 2941 \\
\hline $1 / 2 / 2003$ & 4938 & 2195 & $3 / 16 / 2003$ & 5663 & 2469 & $9 / 21 / 2003$ & 7598 & 2954 \\
\hline $1 / 7 / 2003$ & 4626 & 2095 & $3 / 17 / 2003$ & 5518 & 2433 & $9 / 23 / 2003$ & 7337 & 2863 \\
\hline $1 / 8 / 2003$ & 5249 & 2353 & $3 / 20 / 2003$ & 5519 & 2431 & 9/26/2003 & 7603 & 2955 \\
\hline $1 / 13 / 2003$ & 5332 & 2382 & $3 / 23 / 2003$ & 5519 & 2529 & 9/30/2003 & 7384 & 2891 \\
\hline $1 / 14 / 2003$ & 5485 & 2428 & $3 / 27 / 2003$ & 5166 & 2370 & $10 / 3 / 2003$ & 7484 & 2907 \\
\hline $1 / 16 / 2003$ & 5313 & 2383 & 3/29/2003 & 5701 & 2572 & $10 / 8 / 2003$ & 7661 & 2968 \\
\hline $1 / 17 / 2003$ & 5424 & 2417 & $4 / 3 / 2003$ & 5251 & 2399 & $10 / 12 / 2003$ & 7470 & 2897 \\
\hline $1 / 19 / 2003$ & 5542 & 2483 & $4 / 6 / 2003$ & 5291 & 2404 & $10 / 18 / 2003$ & 7508 & 2917 \\
\hline $1 / 21 / 2003$ & 5667 & 2538 & $4 / 9 / 2003$ & 5508 & 2505 & $10 / 22 / 2003$ & 7314 & 2843 \\
\hline $1 / 22 / 2003$ & 5274 & 2385 & $4 / 11 / 2003$ & 5282 & 2401 & $10 / 23 / 2003$ & 7253 & 2834 \\
\hline $1 / 25 / 2003$ & 5340 & 2402 & $4 / 13 / 2003$ & 5536 & 2487 & & & \\
\hline $1 / 26 / 2003$ & 5367 & 2420 & $4 / 15 / 2003$ & 5520 & 2487 & & & \\
\hline $1 / 27 / 2003$ & 5584 & 2501 & $4 / 18 / 2003$ & 5117 & 2349 & & & \\
\hline $1 / 28 / 2003$ & 5639 & 2531 & $4 / 23 / 2003$ & 5642 & 2534 & & & \\
\hline $1 / 29 / 2003$ & 5430 & 2440 & $4 / 27 / 2003$ & 5327 & 2417 & & & \\
\hline $2 / 1 / 2003$ & 5292 & 2393 & $5 / 1 / 2003$ & 5336 & 2427 & & & \\
\hline $2 / 2 / 2003$ & 5414 & 2445 & $5 / 2 / 2003$ & 5450 & 2464 & & & \\
\hline $2 / 6 / 2003$ & 5772 & 2428 & $5 / 6 / 2003$ & 5521 & 2488 & & & \\
\hline 2/8/2003 & 5438 & 2462 & $5 / 7 / 2003$ & 5233 & 2381 & & & \\
\hline 2/10/2003 & 5662 & 2559 & $5 / 11 / 2003$ & 5505 & 2469 & & & \\
\hline $2 / 11 / 2003$ & 4753 & 2192 & $5 / 14 / 2003$ & 5283 & 2415 & & & \\
\hline $2 / 12 / 2003$ & 4274 & 1992 & $5 / 17 / 2003$ & 5177 & 2366 & & & \\
\hline $2 / 16 / 2003$ & 5412 & 2460 & $5 / 20 / 2003$ & 5280 & 2399 & & & \\
\hline
\end{tabular}


Appendix 5: The $\mathrm{Cl}^{-}$and $\mathrm{SO}_{4}{ }^{2-}$ concentrations (ppm) of the Yuanshan hot spring

\begin{tabular}{|c|c|c|c|c|c|c|c|c|}
\hline Date & $\mathrm{Cl}^{-}$ & $\mathrm{SO}_{4}{ }^{2-}$ & Date & $\mathrm{Cl}^{-}$ & $\mathrm{SO}_{4}{ }^{2-}$ & Date & $\mathrm{Cl}^{-}$ & $\mathrm{SO}_{4}{ }^{2-}$ \\
\hline 3/1/2003 & 52.5 & 6.12 & $6 / 2 / 2003$ & 62.3 & 6.90 & $9 / 2 / 2003$ & 62.8 & 7.64 \\
\hline 3/4/2003 & 51.0 & 6.48 & $6 / 5 / 2003$ & 62.7 & 6.98 & 9/5/2003 & 63.1 & 7.52 \\
\hline 3/7/2003 & 52.0 & 6.42 & 6/8/2003 & 61.8 & 7.60 & 9/8/2003 & 63.2 & 7.60 \\
\hline 3/10/2003 & 54.2 & 6.26 & $6 / 11 / 2003$ & 64.9 & 6.92 & 9/11/2003 & 63.1 & 7.60 \\
\hline 3/13/2003 & 52.8 & 6.10 & $6 / 14 / 2003$ & 62.0 & 7.04 & 9/14/2003 & 62.9 & 8.12 \\
\hline 3/16/2003 & 53.0 & 6.12 & 6/17/2003 & 63.4 & 7.12 & 9/17/2003 & 63.1 & 7.54 \\
\hline 3/19/2003 & 53.7 & 6.48 & 6/20/2003 & 62.8 & 7.58 & 9/20/2003 & 63.7 & 7.70 \\
\hline 3/22/2003 & 51.6 & 6.24 & $6 / 23 / 2003$ & 58.7 & 6.88 & 9/23/2003 & 63.2 & 8.16 \\
\hline 3/25/2003 & 43.2 & 6.10 & 6/26/2003 & 62.4 & 6.80 & 9/26/2003 & 60.9 & 19.50 \\
\hline 3/28/2003 & 43.4 & 6.76 & 7/1/2003 & 61.9 & 6.90 & 9/30/2003 & 34.5 & 7.70 \\
\hline 3/31/2003 & 43.0 & 6.78 & $7 / 4 / 2003$ & 61.8 & 6.94 & $10 / 2 / 2003$ & 62.6 & 7.70 \\
\hline 4/3/2003 & 43.2 & 6.78 & 7/7/2003 & 61.2 & 7.10 & $10 / 5 / 2003$ & 62.8 & 7.88 \\
\hline 4/6/2003 & 42.5 & 6.10 & 7/10/2003 & 61.9 & 6.82 & $10 / 8 / 2003$ & 62.9 & 7.72 \\
\hline 4/9/2003 & 43.2 & 6.06 & 7/13/2003 & 61.0 & 6.86 & $10 / 11 / 2003$ & 62.4 & 8.06 \\
\hline 4/12/2003 & 42.4 & 6.81 & 7/16/2003 & 63.1 & 6.88 & $10 / 14 / 2003$ & 63.4 & 8.32 \\
\hline 4/15/2003 & 43.1 & 6.10 & 7/19/2003 & 62.5 & 6.92 & $10 / 17 / 2003$ & 62.6 & 7.76 \\
\hline 4/18/2003 & 43.0 & 6.78 & 7/22/2003 & 66.3 & 6.72 & $10 / 20 / 2003$ & 62.7 & 7.46 \\
\hline 4/21/2003 & 43.3 & 6.29 & $7 / 25 / 2003$ & 61.9 & 6.74 & & & \\
\hline 4/24/2003 & 43.1 & 6.06 & 7/28/2003 & 61.6 & 6.76 & & & \\
\hline 4/27/2003 & 42.4 & 6.12 & 7/31/2003 & 62.0 & 6.80 & & & \\
\hline 4/30/2003 & 43.7 & 6.33 & 8/3/2003 & 62.4 & 6.80 & & & \\
\hline 5/3/2003 & 43.1 & 6.35 & 8/6/2003 & 61.6 & 6.84 & & & \\
\hline 5/6/2003 & 42.0 & 6.21 & 8/9/2003 & 61.9 & 6.82 & & & \\
\hline 5/9/2003 & 42.5 & 7.48 & $8 / 12 / 2003$ & 61.8 & 8.70 & & & \\
\hline $5 / 12 / 2003$ & 33.8 & 6.80 & $8 / 15 / 2003$ & 55.9 & 6.76 & & & \\
\hline 5/15/2003 & 42.3 & 6.80 & 8/18/2003 & 61.8 & 6.82 & & & \\
\hline $5 / 18 / 2003$ & 25.9 & 6.12 & $8 / 21 / 2003$ & 62.0 & 6.80 & & & \\
\hline $5 / 21 / 2003$ & 42.6 & 6.10 & $8 / 24 / 2003$ & 61.9 & 6.92 & & & \\
\hline $5 / 24 / 2003$ & 42.9 & 6.78 & $8 / 27 / 2003$ & 62.1 & 7.72 & & & \\
\hline $5 / 27 / 2003$ & 42.2 & 6.82 & 8/30/2003 & 63.5 & 7.72 & & & \\
\hline
\end{tabular}


Appendix 6: The $\mathrm{Cl}^{-}$and $\mathrm{SO}_{4}{ }^{2-}$ concentrations (ppm) of the Kuantzeling artesian spring

\begin{tabular}{|c|c|c|c|c|c|c|c|c|}
\hline Date & $\mathrm{Cl}^{-}$ & $\mathrm{SO}_{4}{ }^{2-}$ & Date & $\mathrm{Cl}^{-}$ & $\mathrm{SO}_{4}{ }^{2-}$ & Date & $\mathrm{Cl}^{-}$ & $\mathrm{SO}_{4}{ }^{2-}$ \\
\hline $1 / 7 / 2000$ & 3.17 & 26.6 & $4 / 24 / 2000$ & 2.96 & 26.6 & 7/31/2000 & 2.57 & 23.4 \\
\hline $1 / 10 / 2000$ & 2.58 & 27.4 & $4 / 27 / 2000$ & 2.97 & 24.2 & $8 / 2 / 2000$ & 2.20 & 24.3 \\
\hline $1 / 13 / 2000$ & 2.60 & 28.4 & $4 / 30 / 2000$ & 2.66 & 23.7 & $8 / 4 / 2000$ & 2.09 & 24.6 \\
\hline $1 / 16 / 2000$ & 2.71 & 27.8 & $5 / 3 / 2000$ & 3.14 & 24.1 & $8 / 6 / 2000$ & 2.08 & 21.1 \\
\hline $1 / 19 / 2000$ & 2.40 & 23.8 & $5 / 6 / 2000$ & 3.27 & 24.4 & 8/8/2000 & 2.20 & 24.1 \\
\hline $1 / 22 / 2000$ & 2.48 & 27.8 & $5 / 9 / 2000$ & 2.99 & 23.9 & $8 / 10 / 2000$ & 2.07 & 21.4 \\
\hline $1 / 25 / 2000$ & 2.19 & 25.0 & $5 / 12 / 2000$ & 3.15 & 24.1 & $8 / 12 / 2000$ & 2.03 & 21.5 \\
\hline $1 / 28 / 2000$ & 2.71 & 28.4 & $5 / 15 / 2000$ & 2.91 & 24.9 & $8 / 14 / 2000$ & 2.17 & 21.3 \\
\hline $1 / 31 / 2000$ & 2.72 & 28.4 & $5 / 18 / 2000$ & 3.23 & 24.5 & $8 / 16 / 2000$ & 2.21 & 21.6 \\
\hline $2 / 3 / 2000$ & 3.11 & 26.9 & $5 / 21 / 2000$ & 3.23 & 24.6 & $8 / 18 / 2000$ & 2.48 & 26.0 \\
\hline $2 / 6 / 2000$ & 2.94 & 28.4 & $5 / 24 / 2000$ & 3.15 & 24.9 & $8 / 20 / 2000$ & 2.50 & 27.6 \\
\hline 2/9/2000 & 2.79 & 26.5 & $5 / 27 / 2000$ & 2.91 & 24.4 & $8 / 22 / 2000$ & 1.96 & 21.2 \\
\hline $2 / 12 / 2000$ & 2.78 & 27.9 & $5 / 30 / 2000$ & 3.52 & 24.2 & $8 / 24 / 2000$ & 2.11 & 22.4 \\
\hline $2 / 15 / 2000$ & 2.14 & 24.2 & $6 / 1 / 2000$ & 4.21 & 24.8 & $8 / 26 / 2000$ & 2.11 & 22.2 \\
\hline $2 / 18 / 2000$ & 2.54 & 28.3 & $6 / 4 / 2000$ & 3.30 & 25.0 & $8 / 28 / 2000$ & 1.98 & 21.6 \\
\hline $2 / 21 / 2000$ & 2.20 & 25.6 & $6 / 7 / 2000$ & 2.87 & 23.7 & $8 / 30 / 2000$ & 2.08 & 21.3 \\
\hline $2 / 24 / 2000$ & 2.84 & 27.8 & $6 / 10 / 2000$ & 5.24 & 64.8 & $9 / 1 / 2000$ & 2.20 & 24.6 \\
\hline $2 / 27 / 2000$ & 2.44 & 26.6 & $6 / 13 / 2000$ & 5.55 & 62.4 & $9 / 4 / 2000$ & 2.33 & 27.3 \\
\hline $3 / 1 / 2000$ & 2.60 & 27.7 & $6 / 16 / 2000$ & 4.29 & 24.1 & $9 / 7 / 2000$ & 2.28 & 27.1 \\
\hline $3 / 4 / 2000$ & 2.28 & 25.2 & $6 / 18 / 2000$ & 2.91 & 24.7 & $9 / 10 / 2000$ & 2.54 & 28.3 \\
\hline $3 / 7 / 2000$ & 2.43 & 27.0 & $6 / 19 / 2000$ & 4.12 & 24.1 & $9 / 13 / 2000$ & 2.44 & 28.8 \\
\hline $3 / 10 / 2000$ & 2.57 & 25.8 & $6 / 20 / 2000$ & 4.09 & 25.2 & $9 / 16 / 2000$ & 2.33 & 25.8 \\
\hline 3/13/2000 & 2.11 & 25.2 & $6 / 22 / 2000$ & 3.48 & 27.0 & $9 / 19 / 2000$ & 2.51 & 28.6 \\
\hline $3 / 16 / 2000$ & 2.46 & 24.2 & $6 / 25 / 2000$ & 3.27 & 25.5 & $9 / 22 / 2000$ & 2.61 & 28.9 \\
\hline $3 / 19 / 2000$ & 2.98 & 28.1 & $6 / 28 / 2000$ & 3.53 & 27.6 & $9 / 25 / 2000$ & 2.78 & 29.5 \\
\hline $3 / 22 / 2000$ & 2.98 & 28.8 & $7 / 1 / 2000$ & 3.59 & 27.2 & 9/28/2000 & 2.29 & 28.1 \\
\hline $3 / 25 / 2000$ & 3.05 & 27.7 & $7 / 4 / 2000$ & 3.27 & 26.6 & $9 / 30 / 2000$ & 2.38 & 28.9 \\
\hline $3 / 28 / 2000$ & 2.95 & 28.3 & $7 / 7 / 2000$ & 3.35 & 27.7 & $10 / 1 / 2000$ & 2.48 & 28.2 \\
\hline $3 / 31 / 2000$ & 2.44 & 26.2 & $7 / 10 / 2000$ & 3.48 & 28.8 & $10 / 4 / 2000$ & 2.45 & 27.8 \\
\hline $4 / 3 / 2000$ & 2.20 & 27.6 & $7 / 13 / 2000$ & 3.38 & 28.8 & $10 / 7 / 2000$ & 2.27 & 27.5 \\
\hline $4 / 6 / 2000$ & 2.93 & 29.2 & 7/16/2000 & 4.63 & 26.9 & $10 / 10 / 2000$ & 2.39 & 27.0 \\
\hline $4 / 9 / 2000$ & 2.90 & 25.1 & $7 / 19 / 2000$ & 2.62 & 24.6 & $10 / 13 / 2000$ & 2.26 & 24.3 \\
\hline $4 / 12 / 2000$ & 6.14 & 50.8 & $7 / 22 / 2000$ & 2.95 & 27.7 & $10 / 16 / 2000$ & 2.32 & 26.7 \\
\hline $4 / 15 / 2000$ & 6.43 & 50.1 & $7 / 25 / 2000$ & 2.90 & 27.5 & $10 / 19 / 2000$ & 2.50 & 26.7 \\
\hline $4 / 21 / 2000$ & 2.96 & 26.6 & 7/28/2000 & 3.18 & 27.8 & $10 / 22 / 2000$ & 2.59 & 26.9 \\
\hline
\end{tabular}




\begin{tabular}{|c|c|c|c|c|c|c|c|c|}
\hline $10 / 25 / 2000$ & 2.71 & 26.0 & $2 / 5 / 2001$ & 2.95 & 24.7 & 7/7/2001 & 1.63 & 26.6 \\
\hline $10 / 28 / 2000$ & 2.53 & 26.0 & $2 / 13 / 2001$ & 2.96 & 24.2 & $7 / 11 / 2001$ & 1.60 & 26.2 \\
\hline $10 / 31 / 2000$ & 2.63 & 26.3 & 2/15/2001 & 2.80 & 24.5 & 7/21/2001 & 1.53 & 21.9 \\
\hline $11 / 3 / 2000$ & 2.49 & 26.0 & 2/18/2001 & 2.90 & 24.1 & 8/3/2001 & 1.87 & 23.4 \\
\hline $11 / 6 / 2000$ & 2.92 & 28.2 & 3/3/2001 & 3.23 & 24.2 & 8/8/2001 & 1.65 & 24.9 \\
\hline $11 / 9 / 2000$ & 2.73 & 25.9 & $3 / 6 / 2001$ & 3.33 & 24.1 & $8 / 15 / 2001$ & 1.34 & 24.4 \\
\hline $11 / 12 / 2000$ & 2.86 & 26.2 & 3/8/2001 & 3.04 & 24.1 & 8/20/2001 & 1.89 & 24.9 \\
\hline $11 / 15 / 2000$ & 2.62 & 26.9 & 3/12/2001 & 3.17 & 23.0 & 8/26/2001 & 1.50 & 19.2 \\
\hline $11 / 18 / 2000$ & 2.64 & 27.4 & 3/19/2001 & 2.88 & 21.8 & $8 / 29 / 2001$ & 1.16 & 19.6 \\
\hline $11 / 21 / 2000$ & 2.58 & 26.5 & $3 / 21 / 2001$ & 3.16 & 21.4 & & & \\
\hline $11 / 24 / 2000$ & 3.08 & 27.7 & 3/24/2001 & 3.26 & 24.6 & & & \\
\hline $11 / 27 / 2000$ & 2.79 & 28.0 & 3/29/2001 & 2.90 & 21.9 & & & \\
\hline $11 / 30 / 2000$ & 2.95 & 26.3 & 4/1/2001 & 2.90 & 21.6 & & & \\
\hline $12 / 1 / 2000$ & 2.78 & 27.8 & 4/5/2001 & 2.76 & 23.1 & & & \\
\hline $12 / 4 / 2000$ & 2.78 & 27.5 & 4/9/2001 & 2.92 & 21.1 & & & \\
\hline $12 / 7 / 2000$ & 3.25 & 26.9 & $4 / 14 / 2001$ & 3.07 & 21.0 & & & \\
\hline $12 / 10 / 2000$ & 2.99 & 26.8 & 4/16/2001 & 2.70 & 20.7 & & & \\
\hline $12 / 16 / 2000$ & 2.95 & 26.0 & $4 / 21 / 2001$ & 2.84 & 20.9 & & & \\
\hline $12 / 19 / 2000$ & 2.71 & 25.0 & $4 / 24 / 2001$ & 2.73 & 21.3 & & & \\
\hline $12 / 22 / 2000$ & 2.80 & 26.1 & $4 / 29 / 2001$ & 2.59 & 21.5 & & & \\
\hline $12 / 25 / 2000$ & 3.06 & 25.9 & $5 / 5 / 2001$ & 2.72 & 20.8 & & & \\
\hline $12 / 28 / 2000$ & 2.95 & 26.3 & $5 / 10 / 2001$ & 1.76 & 21.1 & & & \\
\hline $12 / 31 / 2000$ & 2.88 & 27.1 & $5 / 16 / 2001$ & 2.15 & 25.6 & & & \\
\hline $1 / 3 / 2001$ & 3.02 & 26.3 & $5 / 29 / 2001$ & 2.88 & 24.5 & & & \\
\hline 1/9/2001 & 3.35 & 28.0 & 6/3/2001 & 1.56 & 22.0 & & & \\
\hline $1 / 12 / 2001$ & 3.03 & 28.6 & 6/9/2001 & 2.06 & 22.3 & & & \\
\hline $1 / 23 / 2001$ & 3.29 & 26.0 & $6 / 15 / 2001$ & 2.19 & 24.1 & & & \\
\hline $1 / 25 / 2001$ & 2.97 & 25.8 & $6 / 19 / 2001$ & 2.08 & 25.1 & & & \\
\hline $1 / 27 / 2001$ & 3.05 & 24.4 & 6/26/2001 & 1.41 & 24.1 & & & \\
\hline 2/2/2001 & 2.90 & 25.0 & $7 / 1 / 2001$ & 1.74 & 26.1 & & & \\
\hline
\end{tabular}


Appendix 7: The $\mathrm{Cl}^{-}$and $\mathrm{SO}_{4}{ }^{2-}$ concentrations (ppm) of the Meinong groundwater

\begin{tabular}{|c|c|c|c|c|c|c|c|c|}
\hline Date & $\mathrm{Cl}^{-}$ & $\mathrm{SO}_{4}{ }^{2-}$ & Date & $\mathrm{Cl}^{-}$ & $\mathrm{SO}_{4}{ }^{2-}$ & Date & $\mathrm{Cl}^{-}$ & $\mathrm{SO}_{4}{ }^{2-}$ \\
\hline $1 / 5 / 2000$ & 10.6 & 74.2 & $6 / 12 / 2000$ & 12.0 & 80.7 & $11 / 23 / 2000$ & 12.7 & 87.7 \\
\hline $1 / 8 / 2000$ & 10.1 & 72.3 & $6 / 13 / 2000$ & 12.0 & 81.6 & $11 / 30 / 2000$ & 11.3 & 87.4 \\
\hline $1 / 11 / 2000$ & 10.5 & 72.0 & 6/19/2000 & 11.8 & 82.2 & $12 / 7 / 2000$ & 12.7 & 89.0 \\
\hline $1 / 14 / 2000$ & 10.1 & 72.6 & $6 / 29 / 2000$ & 11.9 & 83.7 & $12 / 14 / 2000$ & 10.2 & 85.7 \\
\hline $1 / 17 / 2000$ & 10.2 & 70.5 & 7/3/2000 & 12.5 & 86.3 & $12 / 21 / 2000$ & 12.3 & 86.5 \\
\hline $1 / 20 / 2000$ & 10.2 & 70.1 & $7 / 6 / 2000$ & 13.0 & 84.7 & $12 / 28 / 2000$ & 12.2 & 79.4 \\
\hline $1 / 24 / 2000$ & 11.1 & 69.8 & $7 / 11 / 2000$ & 11.9 & 83.3 & $1 / 4 / 2001$ & 11.5 & 83.6 \\
\hline $1 / 27 / 2000$ & 10.4 & 70.1 & $7 / 14 / 2000$ & 12.0 & 83.1 & $1 / 11 / 2001$ & 13.3 & 89.2 \\
\hline $1 / 28 / 2000$ & 10.2 & 69.9 & $7 / 27 / 2000$ & 12.1 & 86.5 & $1 / 18 / 2001$ & 12.7 & 76.8 \\
\hline 1/31/2000 & 10.5 & 71.9 & $8 / 3 / 2000$ & 12.3 & 90.0 & & & \\
\hline $2 / 10 / 2000$ & 11.2 & 75.6 & $8 / 7 / 2000$ & 12.2 & 91.0 & & & \\
\hline 2/19/2000 & 10.8 & 72.1 & $8 / 11 / 2000$ & 12.2 & 90.9 & & & \\
\hline $2 / 22 / 2000$ & 11.0 & 73.2 & $8 / 16 / 2000$ & 12.5 & 94.0 & & & \\
\hline $3 / 3 / 2000$ & 10.6 & 73.9 & $8 / 22 / 2000$ & 12.4 & 93.2 & & & \\
\hline $3 / 7 / 2000$ & 10.6 & 72.5 & $8 / 28 / 2000$ & 11.4 & 91.3 & & & \\
\hline $3 / 10 / 2000$ & 10.9 & 73.8 & $9 / 2 / 2000$ & 11.0 & 88.5 & & & \\
\hline $3 / 13 / 2000$ & 11.7 & 74.7 & $9 / 7 / 2000$ & 11.4 & 90.6 & & & \\
\hline $3 / 21 / 2000$ & 10.9 & 74.2 & $9 / 11 / 2000$ & 11.0 & 91.9 & & & \\
\hline 3/28/2000 & 11.2 & 74.6 & $9 / 15 / 2000$ & 11.3 & 91.3 & & & \\
\hline $4 / 10 / 2000$ & 11.0 & 73.8 & $9 / 20 / 2000$ & 11.4 & 93.1 & & & \\
\hline 4/17/2000 & 11.1 & 73.1 & $9 / 23 / 2000$ & 12.7 & 96.7 & & & \\
\hline 4/22/2000 & 11.4 & 74.4 & $9 / 26 / 2000$ & 12.3 & 99.5 & & & \\
\hline $4 / 27 / 2000$ & 13.0 & 74.3 & 9/29/2000 & 12.3 & 97.1 & & & \\
\hline $5 / 3 / 2000$ & 13.1 & 74.4 & $10 / 12 / 2000$ & 11.1 & 88.1 & & & \\
\hline $5 / 12 / 2000$ & 11.5 & 73.7 & $10 / 16 / 2000$ & 9.9 & 83.6 & & & \\
\hline $5 / 18 / 2000$ & 11.0 & 72.2 & $10 / 19 / 2000$ & 9.8 & 82.6 & & & \\
\hline $5 / 25 / 2000$ & 12.1 & 73.2 & $10 / 26 / 2000$ & 11.2 & 86.2 & & & \\
\hline $5 / 30 / 2000$ & 12.7 & 85.2 & $11 / 2 / 2000$ & 11.4 & 84.4 & & & \\
\hline $6 / 3 / 2000$ & 12.7 & 83.5 & $11 / 9 / 2000$ & 9.9 & 79.2 & & & \\
\hline $6 / 7 / 2000$ & 12.3 & 84.0 & $11 / 16 / 2000$ & 10.2 & 75.3 & & & \\
\hline
\end{tabular}


Appendix 8: The $\mathrm{Cl}^{-}$and $\mathrm{SO}_{4}{ }^{2-}$ concentrations (ppm) of the Tashu groundwater

\begin{tabular}{|c|c|c|c|c|c|c|c|c|}
\hline Date & $\mathrm{Cl}^{-}$ & $\mathrm{SO}_{4}{ }^{2-}$ & Date & $\mathrm{Cl}^{-}$ & $\mathrm{SO}_{4}{ }^{2-}$ & Date & $\mathrm{Cl}^{-}$ & $\mathrm{SO}_{4}{ }^{2-}$ \\
\hline 11/26/1999 & 13.80 & 54.00 & $4 / 20 / 2000$ & 13.32 & 57.13 & $12 / 23 / 2000$ & 14.63 & 67.32 \\
\hline 11/29/1999 & 13.51 & 61.57 & $4 / 27 / 2000$ & 13.20 & 56.00 & $12 / 29 / 2000$ & 13.59 & 59.62 \\
\hline 11/30/1999 & 13.64 & 61.62 & $5 / 15 / 2000$ & 13.33 & 56.01 & $1 / 4 / 2001$ & 13.89 & 58.22 \\
\hline 12/4/1999 & 13.51 & 62.65 & $5 / 22 / 2000$ & 13.11 & 56.80 & & & \\
\hline 12/7/1999 & 13.70 & 60.25 & $5 / 29 / 2000$ & 13.22 & 56.28 & & & \\
\hline 12/8/1999 & 12.29 & 50.50 & $6 / 5 / 2000$ & 13.07 & 55.73 & & & \\
\hline 12/9/1999 & 12.77 & 57.30 & $6 / 13 / 2000$ & 11.95 & 51.60 & & & \\
\hline 12/10/1999 & 13.39 & 63.02 & $6 / 21 / 2000$ & 13.16 & 54.34 & & & \\
\hline 12/11/1999 & 13.30 & 56.05 & 7/3/2000 & 15.58 & 61.46 & & & \\
\hline 12/14/1999 & 13.47 & 59.46 & $7 / 10 / 2000$ & 15.29 & 58.28 & & & \\
\hline $1 / 3 / 2000$ & 13.50 & 56.57 & 7/27/2000 & 15.49 & 61.16 & & & \\
\hline $1 / 7 / 2000$ & 13.63 & 57.50 & $8 / 9 / 2000$ & 14.78 & 58.56 & & & \\
\hline $1 / 10 / 2000$ & 13.23 & 57.42 & $8 / 16 / 2000$ & 15.60 & 62.48 & & & \\
\hline $1 / 20 / 2000$ & 12.80 & 60.25 & $8 / 24 / 2000$ & 15.27 & 61.87 & & & \\
\hline $1 / 27 / 2000$ & 12.90 & 54.61 & $8 / 30 / 2000$ & 15.27 & 58.70 & & & \\
\hline $1 / 30 / 2000$ & 12.84 & 55.13 & $9 / 15 / 2000$ & 15.08 & 59.46 & & & \\
\hline 2/7/2000 & 10.12 & 55.13 & 9/23/2000 & 15.59 & 62.61 & & & \\
\hline $2 / 15 / 2000$ & 12.90 & 54.80 & $10 / 12 / 2000$ & 15.07 & 59.29 & & & \\
\hline $2 / 18 / 2000$ & 13.09 & 57.30 & $10 / 16 / 2000$ & 14.72 & 60.50 & & & \\
\hline $2 / 21 / 2000$ & 13.07 & 60.29 & $10 / 17 / 2000$ & 13.81 & 53.85 & & & \\
\hline 2/29/2000 & 12.46 & 50.80 & $10 / 18 / 2000$ & 14.14 & 57.32 & & & \\
\hline $3 / 2 / 2000$ & 13.20 & 58.67 & $10 / 24 / 2000$ & 13.86 & 65.61 & & & \\
\hline $3 / 6 / 2000$ & 13.41 & 55.94 & $11 / 5 / 2000$ & 14.33 & 61.60 & & & \\
\hline $3 / 13 / 2000$ & 13.25 & 55.30 & $11 / 11 / 2000$ & 14.03 & 57.90 & & & \\
\hline $3 / 16 / 2000$ & 13.74 & 57.75 & $11 / 17 / 2000$ & 13.76 & 57.20 & & & \\
\hline 3/20/2000 & 13.40 & 57.47 & $11 / 23 / 2000$ & 12.85 & 65.30 & & & \\
\hline $3 / 24 / 2000$ & 13.14 & 55.35 & $11 / 29 / 2000$ & 14.22 & 64.32 & & & \\
\hline $3 / 27 / 2000$ & 13.18 & 52.54 & $12 / 5 / 2000$ & 14.96 & 59.60 & & & \\
\hline $4 / 11 / 2000$ & 13.49 & 56.12 & $12 / 11 / 2000$ & 15.23 & 60.95 & & & \\
\hline 4/17/2000 & 13.13 & 54.06 & $12 / 17 / 2000$ & 15.36 & 61.32 & & & \\
\hline
\end{tabular}


Appendix 9: The $\mathrm{Cl}^{-}$and $\mathrm{SO}_{4}{ }^{2-}$ concentrations (ppm) of the Chaochou groundwater

\begin{tabular}{|c|c|c|c|c|c|c|c|c|}
\hline Date & $\mathrm{Cl}^{-}$ & $\mathrm{SO}_{4}{ }^{2-}$ & Date & $\mathrm{Cl}^{-}$ & $\mathrm{SO}_{4}{ }^{2-}$ & Date & $\mathrm{Cl}^{-}$ & $\mathrm{SO}_{4}{ }^{2-}$ \\
\hline $1 / 8 / 2000$ & 2.68 & 47.72 & $4 / 25 / 2000$ & 2.93 & 46.40 & $8 / 20 / 2000$ & 2.84 & 50.36 \\
\hline $1 / 11 / 2000$ & 2.59 & 47.25 & $5 / 1 / 2000$ & 3.00 & 45.70 & $8 / 23 / 2000$ & 2.93 & 52.37 \\
\hline $1 / 14 / 2000$ & 2.66 & 47.93 & $5 / 4 / 2000$ & 2.80 & 45.64 & $8 / 25 / 2000$ & 2.75 & 49.48 \\
\hline $1 / 17 / 2000$ & 2.65 & 48.15 & $5 / 7 / 2000$ & 2.88 & 45.71 & $8 / 28 / 2000$ & 2.85 & 50.29 \\
\hline $1 / 20 / 2000$ & 2.68 & 48.17 & $5 / 10 / 2000$ & 2.93 & 45.76 & $8 / 31 / 2000$ & 2.55 & 50.05 \\
\hline $1 / 23 / 2000$ & 2.61 & 47.66 & $5 / 13 / 2000$ & 2.82 & 45.86 & $9 / 4 / 2000$ & 2.88 & 52.47 \\
\hline $1 / 26 / 2000$ & 2.61 & 47.09 & $5 / 19 / 2000$ & 2.63 & 45.86 & $9 / 6 / 2000$ & 2.93 & 50.80 \\
\hline $1 / 29 / 2000$ & 2.57 & 47.48 & $5 / 20 / 2000$ & 2.95 & 46.58 & 9/9/2000 & 2.85 & 51.92 \\
\hline $2 / 1 / 2000$ & 2.65 & 47.74 & $5 / 25 / 2000$ & 2.55 & 48.85 & 9/12/2000 & 2.59 & 50.73 \\
\hline $2 / 4 / 2000$ & 2.74 & 48.09 & $5 / 28 / 2000$ & 2.61 & 46.90 & $9 / 15 / 2000$ & 2.65 & 47.65 \\
\hline $2 / 7 / 2000$ & 2.62 & 48.12 & $5 / 31 / 2000$ & 2.92 & 49.24 & $9 / 18 / 2000$ & 2.63 & 52.43 \\
\hline $2 / 10 / 2000$ & 2.65 & 47.97 & $6 / 3 / 2000$ & 2.86 & 48.26 & $9 / 21 / 2000$ & 2.71 & 47.74 \\
\hline $2 / 13 / 2000$ & 2.68 & 48.34 & $6 / 6 / 2000$ & 2.79 & 49.99 & $9 / 24 / 2000$ & 2.86 & 52.14 \\
\hline 2/16/2000 & 2.70 & 48.37 & $6 / 9 / 2000$ & 2.85 & 51.78 & 9/27/2000 & 2.65 & 50.96 \\
\hline $2 / 19 / 2000$ & 2.90 & 47.80 & $6 / 12 / 2000$ & 2.92 & 52.17 & $9 / 30 / 2000$ & 2.34 & 51.42 \\
\hline $2 / 22 / 2000$ & 2.64 & 47.90 & $6 / 15 / 2000$ & 2.81 & 50.20 & $10 / 3 / 2000$ & 2.41 & 49.69 \\
\hline $2 / 25 / 2000$ & 2.73 & 47.33 & $6 / 18 / 2000$ & 2.67 & 50.23 & $10 / 6 / 2000$ & 2.37 & 50.39 \\
\hline $2 / 28 / 2000$ & 2.67 & 47.09 & $6 / 21 / 2000$ & 2.87 & 51.07 & $10 / 9 / 2000$ & 2.68 & 50.75 \\
\hline $3 / 2 / 2000$ & 2.61 & 48.29 & $6 / 24 / 2000$ & 2.68 & 51.18 & $10 / 12 / 2000$ & 2.66 & 49.16 \\
\hline $3 / 5 / 2000$ & 2.67 & 47.57 & $6 / 27 / 2000$ & 2.89 & 50.39 & $10 / 15 / 2000$ & 2.59 & 49.80 \\
\hline $3 / 8 / 2000$ & 2.69 & 47.43 & $7 / 3 / 2000$ & 2.97 & 52.16 & $10 / 18 / 2000$ & 2.49 & 48.59 \\
\hline $3 / 11 / 2000$ & 2.98 & 46.44 & $7 / 6 / 2000$ & 2.88 & 49.50 & $10 / 25 / 2000$ & 2.68 & 47.56 \\
\hline $3 / 14 / 2000$ & 2.70 & 48.45 & $7 / 9 / 2000$ & 2.98 & 51.45 & $11 / 1 / 2000$ & 2.57 & 50.97 \\
\hline 3/17/2000 & 2.54 & 48.20 & $7 / 12 / 2000$ & 2.90 & 50.57 & $11 / 8 / 2000$ & 2.77 & 46.22 \\
\hline 3/20/2000 & 3.04 & 47.91 & $7 / 15 / 2000$ & 2.66 & 50.11 & $11 / 15 / 2000$ & 2.89 & 49.21 \\
\hline 3/23/2000 & 2.66 & 48.67 & $7 / 18 / 2000$ & 2.71 & 49.89 & $11 / 22 / 2000$ & 2.66 & 47.22 \\
\hline $3 / 26 / 2000$ & 2.86 & 47.65 & $7 / 21 / 2000$ & 2.81 & 49.90 & $11 / 29 / 2000$ & 2.67 & 48.36 \\
\hline $3 / 29 / 2000$ & 2.74 & 48.11 & $7 / 24 / 2000$ & 2.95 & 51.38 & $12 / 6 / 2000$ & 2.59 & 51.20 \\
\hline $4 / 1 / 2000$ & 2.93 & 47.04 & $7 / 27 / 2000$ & 2.60 & 49.66 & $12 / 13 / 2000$ & 2.67 & 47.32 \\
\hline $4 / 4 / 2000$ & 2.71 & 47.05 & $7 / 30 / 2000$ & 2.93 & 50.35 & $12 / 20 / 2000$ & 2.75 & 49.13 \\
\hline $4 / 7 / 2000$ & 2.92 & 47.38 & $8 / 2 / 2000$ & 2.74 & 50.12 & $12 / 27 / 2000$ & 2.77 & 48.37 \\
\hline $4 / 10 / 2000$ & 3.01 & 46.35 & $8 / 8 / 2000$ & 2.70 & 50.38 & $1 / 3 / 2001$ & 2.59 & 48.65 \\
\hline 4/13/2000 & 2.52 & 45.64 & $8 / 11 / 2000$ & 2.91 & 50.56 & $1 / 10 / 2001$ & 2.62 & 47.32 \\
\hline $4 / 16 / 2000$ & 2.92 & 46.60 & $8 / 14 / 2000$ & 2.65 & 50.94 & $1 / 17 / 2001$ & 2.62 & 47.37 \\
\hline $4 / 22 / 2000$ & 2.83 & 45.60 & $8 / 17 / 2000$ & 2.85 & 49.55 & & & \\
\hline
\end{tabular}


Appendix 10: The $\mathrm{Cl}^{-}$and $\mathrm{SO}_{4}{ }^{2-}$ concentrations (ppm) of the Yuanshan groundwater

\begin{tabular}{|c|c|c|c|c|c|c|c|c|}
\hline Date & $\mathrm{Cl}^{-}$ & $\mathrm{SO}_{4}{ }^{2-}$ & Date & $\mathrm{Cl}^{-}$ & $\mathrm{SO}_{4}{ }^{2-}$ & Date & $\mathrm{Cl}^{-}$ & $\mathrm{SO}_{4}{ }^{2-}$ \\
\hline 2/27/2003 & 2.25 & 13.54 & 5/8/2003 & 5.09 & 15.62 & 8/20/2003 & 4.56 & 17.94 \\
\hline 2/28/2003 & 2.25 & 14.71 & $5 / 10 / 2003$ & 5.08 & 15.33 & $8 / 22 / 2003$ & 4.70 & 17.87 \\
\hline $3 / 1 / 2003$ & 2.27 & 14.69 & $5 / 15 / 2003$ & 5.27 & 15.43 & $8 / 25 / 2003$ & 4.28 & 17.98 \\
\hline 3/3/2003 & 2.27 & 14.74 & $5 / 17 / 2003$ & 4.99 & 15.39 & $8 / 27 / 2003$ & 4.64 & 18.00 \\
\hline 3/4/2003 & 2.34 & 14.63 & $5 / 20 / 2003$ & 5.04 & 15.49 & $8 / 29 / 2003$ & 4.58 & 17.97 \\
\hline $3 / 6 / 2003$ & 2.30 & 14.54 & $5 / 22 / 2003$ & 4.98 & 15.22 & 9/1/2003 & 4.51 & 18.00 \\
\hline 3/11/2003 & 2.34 & 14.57 & $6 / 11 / 2003$ & 5.09 & 15.62 & 9/3/2003 & 4.52 & 17.95 \\
\hline 3/13/2003 & 2.30 & 15.00 & 6/17/2003 & 5.08 & 15.33 & 9/5/2003 & 4.58 & 17.81 \\
\hline 3/15/2003 & 2.33 & 15.00 & 6/19/2003 & 5.27 & 15.43 & 9/8/2003 & 4.59 & 18.03 \\
\hline $3 / 18 / 2003$ & 2.29 & 15.01 & $6 / 21 / 2003$ & 4.99 & 15.39 & $9 / 12 / 2003$ & 4.57 & 17.82 \\
\hline $3 / 20 / 2003$ & 1.93 & 14.81 & $6 / 24 / 2003$ & 5.04 & 15.49 & $9 / 15 / 2003$ & 17.94 & 5.63 \\
\hline 3/22/2003 & 1.52 & 12.25 & 6/26/2003 & 4.98 & 15.22 & 9/17/2003 & 4.54 & 17.93 \\
\hline 3/24/2003 & 1.90 & 15.00 & $7 / 2 / 2003$ & 5.01 & 15.33 & 9/19/2003 & 4.58 & 17.98 \\
\hline $3 / 25 / 2003$ & 1.93 & 15.50 & $7 / 5 / 2003$ & 4.97 & 15.07 & $9 / 22 / 2003$ & 4.63 & 17.90 \\
\hline $3 / 27 / 2003$ & 1.99 & 15.21 & $7 / 10 / 2003$ & 5.02 & 15.03 & $9 / 24 / 2003$ & 4.55 & 17.83 \\
\hline $3 / 29 / 2003$ & 1.95 & 15.24 & $7 / 14 / 2003$ & 5.09 & 15.35 & $9 / 27 / 2003$ & 4.49 & 17.93 \\
\hline 4/1/2003 & 1.92 & 15.30 & 7/16/2003 & 5.04 & 15.30 & $10 / 1 / 2003$ & 17.33 & 17.70 \\
\hline 4/3/2003 & 2.02 & 13.22 & 7/18/2003 & 4.94 & 15.19 & $10 / 3 / 2003$ & 4.16 & 15.38 \\
\hline 4/8/2003 & 1.92 & 15.35 & $7 / 21 / 2003$ & 7.02 & 15.36 & $10 / 7 / 2003$ & 4.11 & 15.54 \\
\hline 4/10/2003 & 1.94 & 15.36 & $7 / 24 / 2003$ & 4.91 & 15.14 & $10 / 9 / 2003$ & 4.22 & 15.33 \\
\hline 4/15/2003 & 1.95 & 15.46 & 7/28/2003 & 4.27 & 17.77 & $10 / 11 / 2003$ & 4.17 & 15.45 \\
\hline 4/16/2003 & 1.95 & 15.33 & 7/30/2003 & 4.32 & 17.90 & $10 / 13 / 2003$ & 4.10 & 15.38 \\
\hline $4 / 17 / 2003$ & 1.94 & 15.47 & $8 / 1 / 2003$ & 4.29 & 17.73 & $10 / 15 / 2003$ & 4.17 & 15.45 \\
\hline 4/19/2003 & 1.94 & 15.34 & 8/4/2003 & 4.58 & 18.05 & $10 / 17 / 2003$ & 4.17 & 15.54 \\
\hline 4/23/2003 & 1.95 & 15.40 & 8/6/2003 & 4.30 & 17.89 & $10 / 20 / 2003$ & 4.19 & 15.69 \\
\hline 4/26/2003 & 1.95 & 15.45 & 8/8/2003 & 4.29 & 17.74 & & & \\
\hline 4/29/2003 & 1.95 & 15.38 & $8 / 11 / 2003$ & 4.35 & 17.94 & & & \\
\hline 5/1/2003 & 1.96 & 15.38 & $8 / 13 / 2003$ & 4.29 & 17.77 & & & \\
\hline 5/3/2003 & 1.95 & 15.44 & $8 / 15 / 2003$ & 4.57 & 18.19 & & & \\
\hline $5 / 6 / 2003$ & 1.94 & 15.40 & 8/18/2003 & 4.28 & 17.67 & & & \\
\hline
\end{tabular}

